\title{
Epidemiology of primary brain tumors: Current concepts and review of the literature $^{1}$
}

\author{
Margaret Wrensch, ${ }^{2}$ Yuriko Minn, Terri Chew, Melissa Bondy, and Mitchel S. Berger \\ Department of Epidemiology and Biostatistics (M.W., T.C.) and Department of Neurological Surgery and Brain \\ Tumor Research Center (M.S.B.), University of California at San Francisco, San Francisco, CA 94143; \\ Department of Neurology, Stanford University, Stanford, CA 94305 (Y.M.); Department of Epidemiology, The \\ University of Texas M.D. Anderson Cancer Center, University of Texas, Houston, TX 77030 (M.B.)
}

The purpose of this review is to provide a sufficiently detailed perspective on epidemiologic studies of primary brain tumors to encourage multidisciplinary etiologic and prognostic studies among surgeons, neuro-oncologists, epidemiologists, and molecular scientists. Molecular tumor markers that predict survival and treatment response are being identified with hope of even greater gains in this area from emerging array technologies. Regarding risk factors, studies of inherited susceptibility and constitutive polymorphisms in genes pertinent to carcinogenesis (for example, DNA repair and detoxification genes and mutagen sensitivity) have revealed provocative findings. Inverse associations of the history of allergies with glioma risk observed in 3 large studies and reports of inverse associations of glioma with common infections

Received 14 March 2002, accepted 28 June 2002.

${ }^{1}$ This work was supported by the National Cancer Institute Grants RO1CA52689 to Margaret Wrensch, R01CA70917001 to Melissa Bondy, and P01CA55261 to Victor Levin at The University of Texas M.D. Anderson Cancer Center.

\footnotetext{
${ }^{2}$ Address correspondence and reprint requests to Margaret Wrensch, Department of Epidemiology and Biostatistics, Box 1215, 44 Page St. Suite 503, University of California at San Francisco, San Francisco, CA 94102.

${ }^{3}$ Abbreviations used are as follows: CBTRUS, Central Brain Tumor Registry of the United States; $\mathrm{Cl}$, confidence interval; EGFR, epidermal grow th factor receptor; EMF, electromagnetic fields; GBM, glioblastom a multiforme; NOS, not otherwise specified; OR, odds ratio; SEER, Surveillance, Epidemiology, and End Results; SIR, standardized incidence ratio; SV40, simian virus 40 .
}

suggest a possible role of immune factors in glioma genesis or progression. Studies continue to suggest that brain tumors might result from workplace, dietary, and other personal and residential exposures, but studies of cell phone use and power frequency electromagnetic fields have found little to support a causal connection with brain tumors; caveats remain. The only proven causes of brain tumors (that is, rare hereditary syndromes, therapeutic radiation, and immune suppression giving rise to brain lymphomas) account for a small proportion of cases. Progress in understanding primary brain tumors might result from studies of well-defined histologic and molecular tumor types incorporating assessment of potentially relevant information on subject susceptibility and environmental and noninherited endogenous factors (viruses, radiation, and carcinogenic or protective chemical exposures through diet, workplace, oxidative metabolism, or other sources). Such studies will require the cooperation of researchers from many disciplines. Neuro-Oncology 4, 278-299, 2002 (Posted to Neuro-Oncology [serial online], Doc. 02-011, August 27, 2002. URL <neurooncology.mc.duke.edu>)

$\mathrm{P}$ rimary malignant or benign brain tumors were estimated to be newly diagnosed in about 35,519 Americans in 2001 (CBTRUS, 2000). Epidemiologic studies enhance our understanding of this heterogeneous group of diseases in 2 ways. Descriptive studies characterize the incidence of brain tumors and the mortality and survival rates associated with them with respect to histologic tumor type and demographic characteristics of patients affected, such as their age, sex, and geographic region. Analytic epidemiologic studies either compare the 
risk of brain tumors in people with and without certain characteristics (cohort studies) or compare the histories of people with and without brain tumors (case-control studies) to provide information on a wide range of possible risk factors, including diet, smoking, alcohol, occupation and industry, exposure to ionizing or nonionizing radiation, infections, allergies, head trauma, family history, and inherited polymorphisms in genes related to carcinogen metabolism, oxidative metabolism, and DNA repair. Because of the relative rarity of brain tumors, most of the analytic studies are case-control studies.

There is intensifying interest in understanding the causes of brain tumors because the prognosis for patients with glioblastoma and other tumor types remains grim and because dramatic progress in the molecular classification of tumors has led to the possibility of identifying etiologically homogeneous subsets of tumors. Moreover, the rapidly increasing characterization of potentially relevant genes has created an opportunity to determine which genes might make a person susceptible or resistant to brain tumors and which genes might lead to a particular sensitivity to etiologic environmental agents. The hope is that such knowledge will eventually result in feasible strategies for preventing brain tumors. Furthermore, such genes might play a role in disease progression and sensitivity or resistance to radiation or drug treatments.

Our goal is to foster and facilitate multidisciplinary studies among surgeons, neuro-oncologists, epidemiologists, and molecular scientists by providing a current overview of epidemiologic information on primary brain tumors.

\section{Methods of Literature Review}

This article summarizes recent extensive reviews of brain tumor epidemiology (Berleur and Cordier, 1995; Bondy et al., 1994; Bunin, 2000; Davis and McCarthy, 2000; Davis et al., 1999a; Inskip et al., 1995; Preston-Martin and Mack, 1996; Wrensch et al., 1993, 2000a). In addition, we searched the terms [brain tumors or glioma or glioblastoma or brain cancer] and [epidemiology or risk factors] in MEDLINE for relevant articles published between 1999 and 2001 to update the material. We used the cancer registry and online sources for some of the descriptive epidemiology data. For analytical epidemiology, we included case-control and cohort studies, and in some cases, reports of laboratory findings. This review is intended to cover major areas of epidemiologic research on primary brain tumors and highlights promising new areas of research into these debilitating and often rapidly fatal lesions. It is not an exhaustive review of all relevant literature.

\section{Descriptive Epidemiology}

Descriptive epidemiologic studies of brain tumors are based on several regularly updated sources of information, many of which are now available on the Internet. Data sources include the following:

- CBTRUS $^{3}$ (www.cbtrus.org), with statistics on both primary malignant and benign tumors from 14 col- laborating state cancer registries and on primary malignant tumors from the SEER program 19731996. This Web site also provides links to many cancer and brain tumor organizations that may be of interest to health care professionals and brain tumor patients.

- The North American Association of Cancer Registries (www.naaccr.org), with data on the incidence of malignant tumors from 19 states and 2 metropolitan areas, covering about $45 \%$ of the population of the U.S., and from 8 provinces and territories, covering about $90 \%$ of the Canadian population, as well as cancer mortality data from all U.S. states and Canadian provinces and territories.

- The International Agency on Cancer Research (www.iarc.fr), with statistics on the incidence of malignant tumors and mortality rates from 5 continents.

- SEER program (www-seer.ims.nci.nih.gov), with incidence, mortality, and survival statistics on malignant tumors from a variety of U.S. metropolitan areas and states collected since 1973.

Clinical data on brain tumors are also available from the National Cancer Data Base (Fremgen et al., 1999). Davis and Preston-Martin (1998) presented a review of incidence and survival data, and in the thorough review of the descriptive epidemiology of brain tumors, Davis et al. (1999a) discussed in detail issues affecting the interpretation of existing population data and the current population patterns for occurrence of and survival from brain tumors.

Primary brain tumors are among the top 10 causes of cancer-related deaths (American Cancer Society, 1998). Nearly 13,000 people die from these tumors each year in the U.S. (CBTRUS, 2000). About 11 to 12 per 100,000 persons in the U.S. are diagnosed with a primary brain tumor each year, and 6 to 7 per 100,000 are diagnosed with a primary malignant brain tumor. Almost 1 in every 1300 children will develop some form of primary brain tumor before age 20 years (CBTRUS, 1998). Between 1991 and 1995, 23\% of childhood cancers were brain tumors, and about one fourth of childhood cancer deaths were from a malignant brain tumor (Legler et al., 1999). During the same time period, malignant brain tumors accounted for $1 \%$ of all newly diagnosed adult cancers and for $2 \%$ of cancer-related deaths (Legler et al., 1999). Glioma and other neuroepithelial tumors constitute $49 \%$ of primary brain tumors, and meningiomas are the next most frequent histologic type $(27 \%)$. More information and graphs of percent of tumors by histologic type and site in the brain can be found at the CBTRUS Web site (http:// www.cbtrus.org/2001/2001products.htm).

\section{Age and Sex of Patients}

For all primary brain tumors, the patient's average age at onset is about 54 years. For glioblastoma and meningioma, the average age at onset is 62 years (CBTRUS, 2000). Age distributions differ by tumor site and histology type (Fig. 1), suggesting the likelihood of many different etiologic factors for the different histologic types. For example, the incidence of meningioma increases with 


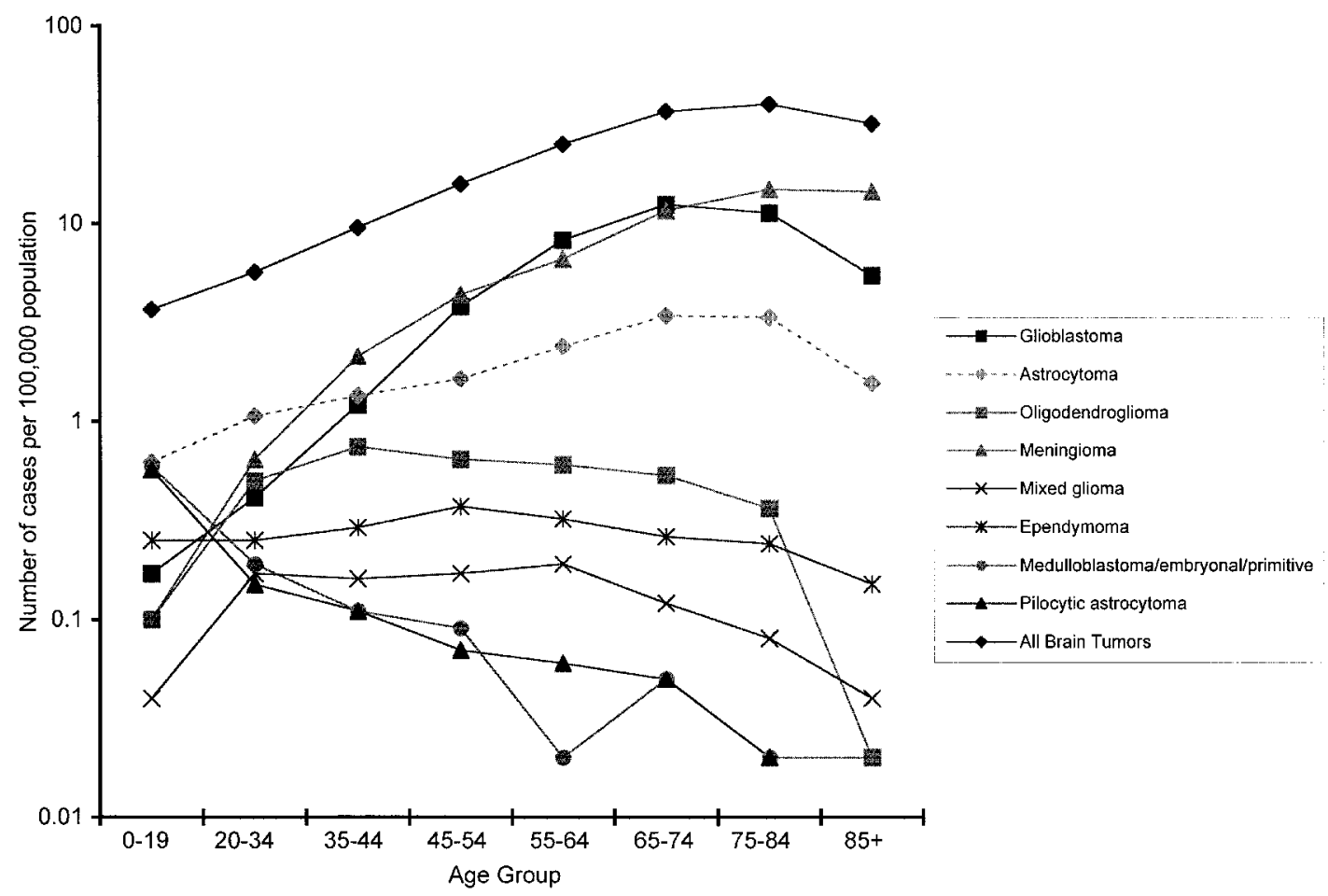

Fig. 1. Incidence rates of primary brain tumors by major neuroepithelial tissue and meningeal histologic types and age group, CBTRUS, 1992-1997. The category All Brain Tumors includes some specific types not individually shown (tumors of cranial and spinal nerves, hemangioblastomas, primary lymphomas, germ cell tumors, and tumors of the sellar region). The Astrocytoma category includes diffuse astrocytomas, anaplastic astrocytomas, unique astrocytoma variants, and astrocytomas not otherwise specified.

increasing age, except for a slight decline in the 85 years and older age group. Conversely, astrocytoma and glioblastoma peak in incidence at age 65 to 74 years, and oligodendroglioma at age 35 to 44 years. Some of this variation may reflect differing diagnostic practices and access to diagnosis in different age groups. It seems likely that the duration of exposure required for malignant transformation, the number of genetic alterations required to produce clinical disease, or poorer immune surveillance with advancing age may account for those tumor types that increase in incidence with age. An intriguing and as yet incompletely explained feature of brain tumor epidemiology is a peak in incidence in young children, some, but not all, of which is attributable to medulloblastoma and other tumors of primitive neuroectodermal origin.

Meningiomas affect about $80 \%$ more females than males; tumors of cranial and spinal nerves and of the sellar region affect males and females almost equally; and the remaining types of primary brain tumors are more common in males than in females (Surawicz et al., 1999). For example, gliomas affect about $40 \%$ more males than females (Surawicz et al., 1999). A recent study from New York state showed that the sex differential (greater incidence in males) in glioblastoma began to be evident around the age of menarche, was greatest around the age of menopause, and decreased thereafter, suggesting that female hormones may have a protective effect (McKinley et al., 2000). Any comprehensive theory of the distribution and causes of brain tumors should explain the bio- logic and social factors that account for these consistently observed sex differences.

\section{Time Trends in Incidence and Mortality}

Interpreting increases in incidence of primary malignant brain tumors (particularly among the elderly) has been complicated by and attributed mainly to improved diagnostic procedures with CT and MRI, a greater availability of neurosurgeons, changing patterns of access to medical care, diagnostic changes, and evolving medical approaches toward elderly patients (Davis et al., 1997; Helseth, 1995; Legler et al., 1999).

Two recent reports use the SEER incidence data and the National Center for Health Statistics mortality data (Legler et al., 1999; Smith et al., 1998) to characterize time trends in primary malignant brain tumor incidence and mortality rates. Among children under 14 years old and adults 70 years old and older, incidence rates for brain malignancies were significantly higher from 1991 to 1995 than from 1975 to 1979 (Legler et al., 1999). In the 15- to 44-year-old age group, there were no meaningful differences in overall rates between the 2 time periods, and for people in the 45- to 64-year-old age group, rates were actually somewhat lower for the more recent time period. Examining the changes in the slope of the time trends, Legler's group attributed the quite dramatic time trends for older age groups (including the 3-fold increased rates for people aged 85 years and older) from 1975-1979 to 1991-1995 to increased MRI use and 
physicians' increased willingness to evaluate older patients (Legler et al., 1999). There was an abrupt rise in incidence rates from 1983 to 1986 for those under age 15 years combined with a decline in mortality rates for this age group over that time period. In the absence of any breakthroughs in therapies, this observation led Smith et al. (1998) to propose that changes made in the histologic classification of brain tumors around 19841985 may have led to tumors previously classified as "benign," and, therefore, not counted among SEER cases being classified as "malignant" (Linet et al., 1999). Another explanation proposed is that the pediatric brain tumor incidence rates may have been influenced by an abrupt change in pediatric practice in the early 1980s when doctors began to prescribe more acetaminophen and less aspirin for children (Varner, 1999); although aspirin was well established as a preventive for colon cancer, data did not exist to support a protective effect against brain tumors (Smith et al., 1999). Another hypothesis for the rise in 1983-1986 was that increased use of MRI detected childhood brain tumors earlier in the course of the disease; however, rates did not subsequently decline as would be expected if this explanation were true (Smith et al., 1999).

Examination of incidence rate time trends of highgrade versus low-grade gliomas (classified by criteria given in Prados et al., 1998) showed a near convergence of rates of high-grade and low-grade gliomas among people aged 15 to 44 years, but a dramatic divergence of rates of high-grade (increasing or stable trends) and low-grade (decreasing trends) gliomas among those aged 45 years or older (Legler et al., 1999). Although changes in diagnostic capabilities over the 20-year period provided a plausible explanation, the possibility exists that some factors might have emerged that may provide some protection against low-grade tumors (Legler et al., 1999).

Using data compiled by CBTRUS from 6 populationbased state cancer registries that collected information on both benign and malignant brain tumors, Jukich et al. (2001) showed that, from 1985 to 1994, incidence rates remained more or less constant for medulloblastoma (and other primitive neuroectodermal tumors), craniopharyngioma, meningioma, and mixed glioma. Increased incidence rates for glioblastoma, oligodendroglioma, and astrocytoma (excluding NOS tumors) were balanced by decreased incidence of glioma-NOS, astrocytoma-NOS, and any brain tumorNOS, suggesting that the increases in specific gliomas may have been artifactual. The increases noted for ependymomas, nerve sheath tumors, and pituitary tumors could not be attributed to diagnostic practice, and the authors recommended further investigation of reasons for those increases. In Sweden, incidence of childhood astrocytoma among those aged 0-15 showed a statistically significant increase from 1973 to 1992, and increased more among girls than boys (Hjalmars et al., 1999). Hjalmars et al. argue that since the increase is largely confined to girls, diagnostic changes are not likely to explain their finding. No increases were observed for ependymomas, primitive neuroectodermal tumors, or medulloblastomas.

Although environmental factors have been implicated in some analytic epidemiologic studies, as discussed below, no risk factors accounting for a large percentage of brain tumors have yet to be identified. For this reason, no attempts have been made to explain the temporal trends quantitatively on the basis of changes in environmental factors. One intriguing possibility is that allergic conditions, which have been increasing in incidence, might confer protection against low-grade but not high-grade gliomas (Schlehofer et al., 1999; Wiemels et al., 2002). Diagnostic discrepancies abound for malignant brain tumors, which further complicates attempts to characterize and interpret time trends. In a study of nearly 500 gliomas diagnosed in adults in the San Francisco Bay Area between 1991 and 1994, Aldape et al. (2000) found a good concordance of diagnoses between the initial report and a uniform review by 1 neuropathologist for certain categories of brain tumors, such as GBM (95\%), but very poor concordance for other categories, such as anaplastic astrocytoma $(57 \%)$ and astrocytoma (38\%). Efforts to standardize histopathologic characterization of these complex tumors will facilitate interpretation of future trends (Davis et al., 1997; Karak et al., 2000). At present, comparisons across time periods or across studies are problematic. Incidence rates may differ among studies simply because of differences in definitions and methodologies, and registry data suffer from ascertainment biases attributable to reporting differences and variability in the availability of health care. For example, a recent population-based study in 2 English counties found very high brain tumor rates of 21 per 100,000 population, a rate that was attributed to exhaustive case finding efforts (20\% of the cases had not been hospitalized) (Pobereskin and Chadduck, 2000). The complexity of the anatomic, pathologic, and clinical classifications of brain tumors is itself problematic, and there is controversy about how some tumor histologies, especially mixed tumor types, may be classified correctly. In the future, this difficulty may warrant increased use of genetic or other markers in conjunction with neuropathologic diagnosis. Above all, a uniform, accurate, and unbiased method for registration of both benign and malignant brain tumors in adults and children (Davis et al., 1997; Gurney et al., 1999) would help clarify variations in the incidence of brain tumors.

\section{Geographic and Ethnic Variation}

Interpretation of geographic and ethnic variations in the incidence of brain tumors is confounded not only by ascertainment bias but also by inconsistent reporting. Access to health care is one influential factor, as reported rates for primary malignant brain tumors tend to be higher in countries with more accessible and highly developed medical care (Inskip et al., 1995; Preston-Martin and Mack, 1996). Among other influences are cultural, ethnic, or geographic differences in risk factors. The incidence rate for malignant brain tumors in Japan is less than half that in Northern Europe. In the U.S., glioma affects more whites than blacks, but the incidence of meningioma is nearly equal among blacks and whites. These differences cannot be attributed only to differences between blacks and whites in their access to health care or in diagnostic practices (Surawicz et al., 1999). The absolute variation in brain tumor incidence rates from 
high-risk to low-risk areas in both the U.S. and the world is about 4- to 5-fold. In contrast, 20-fold differences have been observed for lung cancer and 150-fold differences for melanoma (Inskip et al., 1995).

The Atlas of Cancer Mortality in the United States (Devesa et al., 1999) shows higher death rates from malignant brain tumor for 1970-1994 among white men and women in Mississippi, Alabama, Arkansas, Tennessee, and Kentucky, as well as parts of North and South Carolina, Texas, Kansas, Iowa, Minnesota, Michigan, North and South Dakota, Wisconsin, Washington, and Oregon. Most of New England, Arizona, New Mexico, Wyoming, southwestern Texas and Nevada had lower rates of death from brain malignancies. As with international comparisons, interpretation of these geographic differences is complicated by variations in diagnostic and reporting practices.

Singh and Siahpush (2001) recently reported that American-born men and women have lower mortality rates for brain cancer, stomach cancer, and infections than do foreign-born Americans. Foreign-born Americans have lower overall mortality rates than do U.S.-born Americans. In the San Francisco Bay Area, non-Hispanic whites have higher incidence rates of brain malignancies than do white Hispanics, blacks, Chinese, Japanese, and Filipinos (Glaser et al., 1996). This is true for both males and females. Chen et al. (2001) showed that, among adults with astrocytic gliomas-GBM, anaplastic astrocytoma, and astrocytoma-diagnosed in the Bay Area between 1991 and 1994, whites were less likely than nonwhites to have tumors containing mutations in TP53 gene exons 5-8 (13\% versus $42 \%)$. Whites were much more likely than nonwhites to have tumors that accumulated $\mathrm{p} 53$ protein in the absence of demonstrable TP53 mutation (74\% versus $50 \%)$ and were somewhat more likely to have tumors that neither accumulated $\mathrm{p} 53$ protein nor had mutations in the TP53 gene $(13 \%$ versus $8 \%)$. Age- and sex-adjusted comparisons were statistically significant. This was the first such report and clearly requires replication. For example, it is possible, although it seems unlikely, that the diagnosis - rather than the occurrence-of different molecular subtypes varies by ethnicity. However, the findings, combined with the intriguing findings of a much lower occurrence of CDKN2A/p16 ink4a deletion and mutation among Japanese patients with glioma, compared with American and European white patients (Mochizuki et al., 1999), clearly suggest that further research into ethnic differences in molecular subtypes of gliomas is warranted.

\section{Survival and Prognostic Factors}

For all ages and all brain tumor types in the U.S., the 5 -year survival rate is $20 \%(95 \%$ CI $18 \%-22 \%$ ) (Davis et al., 1998). Another survival measure of interest is the conditional probability of survival to 5 years given survival the first 2 years (Davis et al., 1999b). In the U.S. between 1979 and 1993, the conditional probability of surviving another 3 years after survival to 2 years for all patients with primary malignant brain and other tumors of the CNS was $76.2 \%(95 \%$ CI $74.8 \%-77.6 \%)$, and for patients with any tumor except glioblastoma, survival to 5 years after survival to 2 years was greater than $60 \%$.
Survival is known to be strongly related to patient age and histologic type (Fig. 2) (CBTRUS, 2000). Patients with GBM consistently have the poorest survival in all age groups, and within any histologic type, older patients have poorer survival than younger patients. As shown in Fig. 2, the pediatric (under age 20 years) and younger adult populations (age 20-44 years) have much better survival than do older adults within each histologic type of primary malignant brain tumor. An exception is medulloblastoma or embryonal primitive tumor, which rarely occurs in those over age 44 years. Among children, those diagnosed before age 3 years have shown poorer survival than do children diagnosed at ages 3 to 14 years (Grovas et al., 1997). For all primary malignant brain tumors combined, the 5-year survival rate in children under age 14 years is $72 \%$.

The very poor survival associated with most gliomas has important implications for designing etiologic studies. For example, incident population-based studies must often rely on proxy respondents because of practical difficulties in identifying patients with aggressive disease before death. Furthermore, interpretations of associations for polymorphisms or other factors measured in blood or buccal specimens must consider whether the associations reflect etiologic or prognostic relationships between the factor and the disease. This has led some investigators to ascertain and interview cases in the hospital at the time of diagnosis or surgery, but such an approach can lead to difficulties in identifying appropriate controls to the hospital-based series, and there may be epidemiologically relevant differences in types of cases treated at different hospitals.

For all patients with meningioma-whether benign, atypical, or malignant-overall survival rates are $81 \%$ at 2 years and $69 \%$ at 5 years (McCarthy et al., 1998), but for malignant meningioma only, the 5-year survival rate is $54.6 \%$. As with other primary brain tumors, patients who are older at diagnosis have poorer prognosis from meningioma. For patients with a benign tumor that has been completely resected, the 5 -year recurrence rate is $20.5 \%$.

Overall survival for primary malignant brain tumors has not improved much since the early 1970s (Legler et al., 1999), but this too varies by age and histologic type. For example, there were modest gains in survival between 1975 and 1995 for people younger than 65 years, but virtually no change in survival for patients aged 65 years and older. Although little progress has been made in survival from glioblastoma in 20 years, 5 -year survival rates for patients with medulloblastoma increased $20 \%$ from the 1970 s to the 1980s. More recently, the rates have leveled off (Davis et al., 1998).

Although no factors yet identified are as strong prognostic indicators as age and histology, other factors have been shown to influence survival. In all but 2 of 17 European countries, 5 -year survival rates were somewhat better for women with primary malignant brain tumors than for men with the same tumors (20\% versus $17 \%$ ) (Sant et al., 1998). The location of a tumor and the extent of tumor resection are also factors predicting overall or progression-free survival (Curran et al., 1993; Davis et al., 


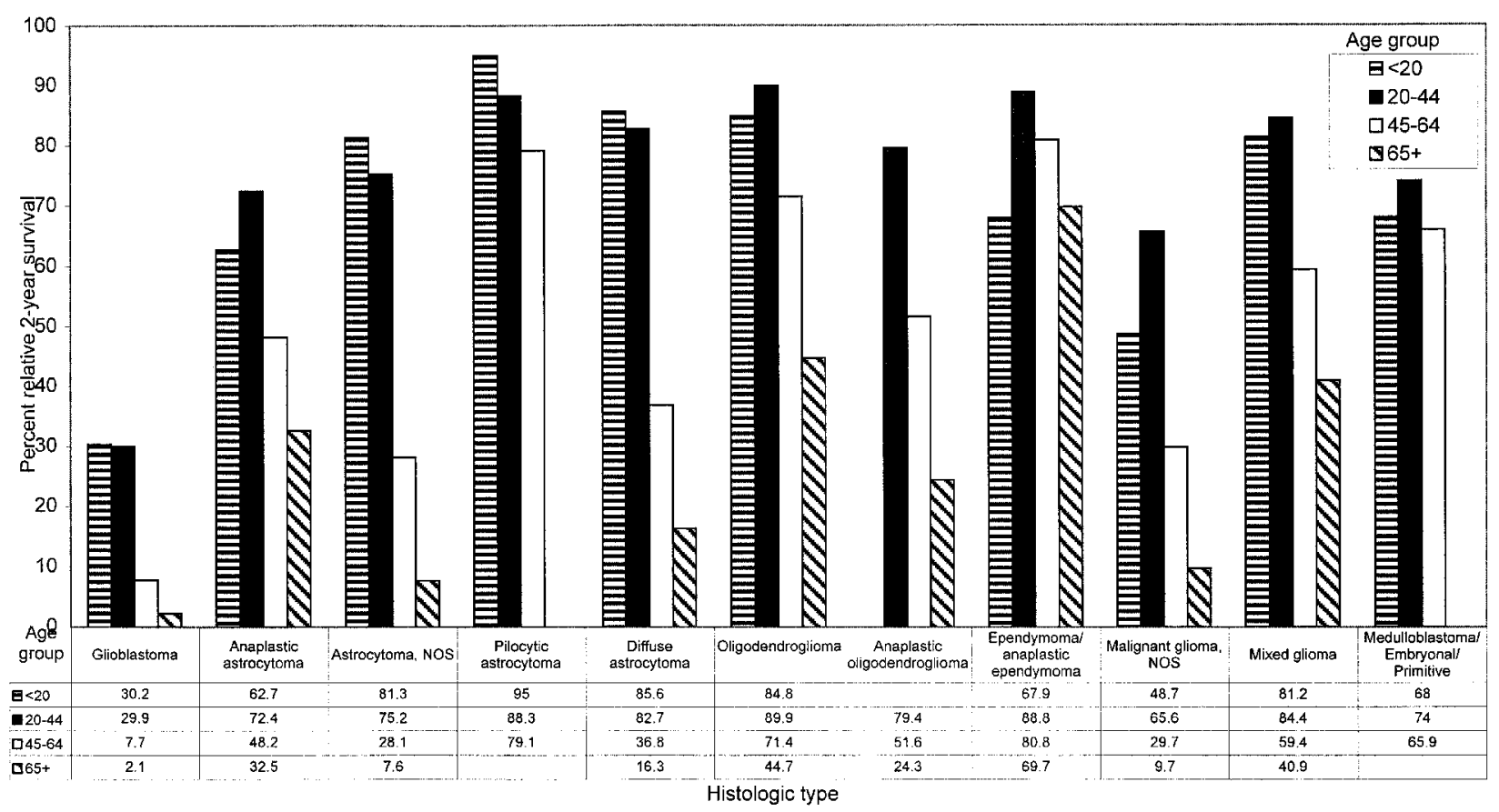

Fig. 2. Two-year relative survival rates for primary malignant brain tumors by age group, Surveillance Epidemiology and End Results (SEER) data, 1973-1996. (Compiled by the Central Brain Tumor Registry of the United States.)

Table 1. Recent studies of tumor markers related to primary brain tumor survival

Tumor type

Molecular markers studied relating to survival/prognosis ${ }^{\mathrm{a}}$

Reference

Glioblastoma

$\downarrow$ Patients aged $<55$ years; EGFR overexpression in TP53 normal tumors

Simmons et al., 2001

$\downarrow$ Ki-67 (MIB-1) labeling index

Scott et al., 1999

$\downarrow$ Cathepsin $B$ expression in tumor endothelial cells

Strojnik et al., 1999

Medulloblastoma and other PNETs

$\downarrow$ Ki-67 (MIB-1) expression

$\uparrow$ TrkC mRNA

Grotzer et al., 2001

Grotzer et al., 2000

Anaplastic oligodendroglioma

$\uparrow$ Loss of chromosome $1 p$ and $19 q$

$\downarrow C D K N 2 \mathrm{~A}$ deletions

Cairncross et al., 1998

Astrocytoma (various grades)

$\uparrow$ p27kip1 expression

Mizumatsu et al., 1999

Only studies that controlled for age and grade are included.

a $\downarrow$ Expression is inversely related to survival; $\uparrow$ expression is positively related to survival.

1999b; Horn et al., 1999; Lopez-Gonzalez and Sotelo, 2000; Nakamura et al., 2000).

Molecular and genetic markers within the tumors also may have prognostic value (Cairncross et al., 1998; Grotzer et al., 2001; Hagel et al., 1999; Huncharek and Kupelnick, 2000; Mizumatsu et al., 1999; Simmons et al., 2001; Strojnik et al., 1999) as summarized in Table 1. For example, Simmons et al. (2001) recently showed a complex relationship of survival with the patient's age and the p53 and EGFR characteristics of the tumor in 110 patients with GBM. Overall, there was no difference in survival regardless of whether the tumor did or did not overexpress EGFR, exhibit p53 immunopositivity, or have p53 mutations. However, when they examined those characteristics in patients younger or older than median age, they found poorer survival among younger patients whose tumors overexpressed EFGR but had normal p53 immunohistochemistry. They confirmed this finding in an independent series of patients. Among children with medulloblastoma or other primitive neuroectodermal brain tumors, those with tumors staining highest for Ki-67 (MIB-1) immunohistochemistry had statistically significant greater risk of progression and death (Grotzer et al., 2001). However, 5-year survival for patients with primitive neuroectodermal brain tumors expressing high levels of neurotrophin receptor TrkC mRNA was $89 \%$ compared with $47 \%$ when low or no levels of neurotrophin receptor TrkC mRNA were expressed (Grotzer et al., 2000).

The devastating prognosis for most patients with GBM demands research to determine factors influencing long-term survival. In one such study of 689 patients with GBM (Scott et al., 1999), only 15 patients survived 3 years or more. The youngest patients and patients with a higher Karnofsky performance status at diagnosis were more likely to be longer-term survivors. Patients with 
long-term survival tended to have lower Ki-67 labeling index compared with controls. Of note is that 14 longterm survivors whose initial diagnosis was GBM were excluded from this study because further pathologic review changed the diagnosis to malignant oligodendroglioma, malignant oligoastrocytoma, malignant astrocytoma, or medulloblastoma.

Another important consideration relevant to prognosis and survival is the reason for progression from less aggressive or benign tumors to more aggressive or malignant tumors. According to James et al. (2002), the only tumor types for which there is sufficiently convincing data to propose specific alterations responsible for progression from lower to higher stage are those from astrocytoma to anaplastic astrocytoma to glioblastoma; p53 modifications are inversely related to stage, whereas changes in $p 14^{a r f}, E G F R, C D K N 2 A$, and PTEN are more common in higher-stage tumors. Clearly, there is still enormous work to be done to systematically characterize the molecular alterations in primary brain tumors and to study the relationships of important modifications to etiology, progression, and prognosis.

\section{Prevalence Estimates}

Prevalence rates reflect incidence and survival and shed light on the extent of disease burden, especially for diseases with relatively long survival (for example, meningioma). Davis et al. (2001) recently published the first available prevalence estimates of primary brain tumors for the U.S. Primary benign brain tumors had an estimated prevalence of 97.5 per 100,000 population for the year 2000, emphasizing the need for further studies on etiology and quality-of-life issues relating to these tumors.

\section{Analytic Studies of Risk Factors}

There is little consensus about the nature and magnitude of the risk factors for primary brain tumors. These tumors are highly heterogeneous histologically. Definitions and classifications of tumors often differ from one study to another. This, together with retrospective assessments of exposure to risk factors and undefined latency periods, make for imprecise estimates of associations. These limitations also often make it difficult to compare studies. Differences in the eligibility criteria established for patients and control groups and the use of proxies further complicate the synthesis of results among studies. Moreover, certain biologic and physiologic characteristics of the brain itself, such as the bloodbrain barrier, add challenges to determining the risk factors for brain tumors. Table 2 summarizes categories of factors that have been studied in relationship to primary brain tumors. Most studies have been of primary malignant brain tumors (which predominantly are gliomas), but increasingly studies are reporting findings for meningiomas. Because the numerous limitations mentioned above make it difficult to briefly summarize whether or not many of the factors studied are in fact related to primary brain tumors, we refer readers to the text below for interpretations of the nature of the associations found for these factors.
Table 2. Factors studied in relationship to risk of primary brain tumors of neuroepithelial tissue or meninges Hereditary syndromes ${ }^{\text {a: }}$ tuberous sclerosis, neurofibromatosis
types 1 and 2 , nevoid basal cell carcinoma syndrome, and ade-
nomatous polyposis syndromes, Li-Fraumeni cancer family syndrome (inherited $p 53$ mutations)

Family history of brain tumors

Constitutive polymorphisms in glutathione transferases, cytochrome p450 2D6 and $1 \mathrm{~A} 1, \mathrm{~N}$-acetyltransferase, ERCC1 and $E R C C 2$, other carcinogen metabolizing, DNA repair, and immune function genes

Lymphocyte mutagen sensitivity to gamma radiation

\section{Prior cancers}

Infectious agents or immunologic response: viruses (common colds, influenza, varicella zoster virus, BK virus, JC virus, others), Toxoplasma gondii

Allergies

\section{Head trauma}

Epilepsy, seizures, or convulsions

Drugs and medications

Diet and vitamins: nitrosamine/nitrosamide/nitrate/nitrite consumption, calcium, food frequency, cured foods

Tobacco smoke exposures

Alcohol

Hair dyes and sprays

Traffic-related air pollution

Occupations and industries: synthetic rubber manufacturing, vinyl chloride, petroleum refining/production work, licensed pesticide applicators, agricultural work, others (see text), parental workplace exposures

Ionizing radiation: therapeutic ${ }^{a}$; diagnostic and other sources Cellular telephones

Other radio frequency exposures

Power frequency electromagnetic field

Abbreviations: ERCC2, excision repair cross-complementing rodent repair deficiency, complementation group 2 (xeroderma pigmentosum D).

${ }^{a}$ These are the only factors that have been proven to cause primary brain tumors of neuroepithelial tissue or meninges. Evidence for or against associations of other factors is presented in the text.

Primary brain tumors are thought to develop through accumulation of genetic alterations that permit cells to evade normal regulatory mechanisms and escape destruction by the immune system. In addition to inherited alterations in crucial genes that control the cell cycle, such as TP53, those chemical, physical, and biologic agents that damage DNA are suspected potential neurocarcinogens. Unraveling the genetic, molecular, and cytogenetic errors in primary brain tumors is important in determining their pathogenesis. Cytogenetic and molecular studies have shown tumor subtypes or patterns within the larger homogeneous histologic categories, such as glioblastoma or astrocytoma (Kleihues and Ohgaki, 2000). James et al. (2002) recently summarized the genetic and molecular changes thought to be causally related to primary CNS tumor formation. Important modifications mentioned for glioblastomas and anaplastic astrocytomas that occur in $5 \%$ to $40 \%$ of these tumors include EGFR amplification and mutation, amplification of CDK4 or MDM2, and deletion or mutation of TP53, RB, or PTEN. For astrocytomas, TP53 is deleted or mutated in $30 \%$ to $40 \%$ of 
tumors. Chromosome $1 \mathrm{p}$ and $19 \mathrm{q}$ are deleted in $40 \%$ to $90 \%$ of oligodendroglial tumors. Chromosome 22 is deleted in about $25 \%$ to $50 \%$ of ependymomas. Varying proportions of medulloblastomas display amplification of MYCN and CMYC and deletion or mutation of PTCH or deletion of chromosome $17 \mathrm{p}$. About $20 \%$ to $30 \%$ of pilocytic astrocytomas have deletion of chromosome $17 \mathrm{q}$. NF2 is deleted or mutated in about $40 \%$ to $50 \%$ of meningiomas or schwannomas, and VHL is deleted or mutated in about $15 \%$ of hemangioblastoma tumors. This very brief summary emphasizes the enormous heterogeneity of molecular modifications within and between histologic types of primary brain tumors and indicates that the causal lesions identified thus far do not account for a substantial proportion of cases in most histologic types. However, as work continues in elucidating patterns of molecular change with tumors, a more precise classification of brain tumors might be developed, making it possible to identify groups of tumors that are more homogeneous than current histologic groupings with respect to causal factors.

\section{Hereditary Syndromes}

Bondy et al. (1994) have reviewed the genetic and familial factors implicated in brain tumors. There is convincing evidence that certain inherited genes may strongly influence the risk of developing primary brain tumors. A person who inherits such a rare gene or chromosomal abnormality that greatly increases the chances of developing a tumor is said to have a genetic predisposition. Some hereditary syndromes - such as tuberous sclerosis, neurofibromatosis types 1 and 2, nevoid basal cell carcinoma syndrome, and syndromes involving adenomatous polyps - seem to pose a genetic predisposition to brain tumors (Bondy et al., 1994). Narod et al. (1991) estimated that genetic predisposition was a factor in only about $2 \%$ of brain tumors diagnosed in children in Great Britain. In a population-based study of 500 adults with glioma in San Francisco (Wrensch et al., 1997), less than $1 \%$ had a known hereditary syndrome -1 had tuberous sclerosis and 3 had neurofibromatosis. Although it is thought that genetic predisposition is influential in relatively few brain tumors $(5 \%-10 \%$; Narod et al., 1991), the proportion may be underestimated because some hereditary syndromes are not readily diagnosed and because patients with a brain tumor are not routinely referred to a clinical geneticist.

Discovery that some families with the hereditary LiFraumeni cancer family syndrome inherited mutated TP 53 led to studies revealing the importance of p53 in many human cancers, including brain tumors (Nichols et al., 2001). Li et al. (1998), reporting a population-based study of adults who developed glioma, showed that more patients whose tumors had TP53 mutations had a firstdegree relative affected with cancer (58\% versus $42 \%$ ), and more had a personal history of a previous cancer (17\% versus $8 \%$ ). Germline TP53 mutations have been more frequently found in patients who have multifocal glioma, glioma and another primary malignancy or a family history of cancer than in patients with other brain tumors (Kyritsis et al., 1994). One study designed to identify germline mutations in genes mutated, deleted, or amplified in sporadic gliomas showed no evidence of germline mutations of $C D K 4, p 16$, and $p 15$ (Gao et al., 1997). Currently, research in this area is focused on determining the frequency of TP53 mutations in tumors and on correlations between specific TP53 mutations and specific exposures. Alterations in other important cellcycle regulators in tumors, such as $p 16, R B$, and $M D M 2$, are also being evaluated.

\section{Familial Aggregation}

Although a disease that affects generations in a family could suggest a genetic etiology, a family's common exposure to environmental agents may also influence the development of the disease. Whereas some researchers have reported significant familial aggregation of brain tumors and of familial aggregation of brain tumors with other cancers, others have not. The reported relative risks of brain tumors among family members of brain tumor cases range from nearly 1 to 10 (reviewed in Bondy et al., 1994; Hemminki et al., 2000; Malmer et al., 1999; Wrensch et al., 1997). Similarly, not all studies of siblings, and no studies of twins, have supported a simple genetic etiology. In a family study of 250 children with brain tumors, Bondy et al. (1994) showed with segregation analysis that the small amount of familial aggregation was due to multifactorial inheritance and could not be due only to chance. Segregation analyses of families of more than 600 adult patients with glioma showed that a polygenic model best explained the pattern of occurrence of brain tumors (de Andrade et al., 2001). Segregation analyses of 2141 first-degree relatives of 297 glioma families did not reject a multifactorial model, but an autosomal recessive model provided the best fit (Malmer et al., 2001). The study estimated that $5 \%$ of all glioma cases were familial. Grossman et al. (1999) showed brain tumors can occur in families without a known predisposing hereditary disease and that the pattern of occurrence in many families suggests environmental causes.

\section{Polymorphisms (Common Variations) in Genes Relevant to Cancer Causation or Prevention}

Given that available evidence suggests that only a small proportion of primary brain tumors are likely to be due to the effects of inherited rare mutations in highly penetrant genes, investigators are beginning to turn their attention to polymorphisms in genes that might influence susceptibility to brain tumors in concert with environmental exposures. Genetic alterations that affect oxidative metabolism, detoxification of carcinogens, DNA stability and repair, or immune response are candidates that might plausibly confer genetic susceptibility to brain tumors and other cancers. Studies of genetic polymorphisms and their influence on susceptibility to carcinogenic exposures have focused mainly on cancers related to tobacco smoking, but recent advances in genetic technology have made possible the epidemiologic evaluation of polymorphisms potentially relevant to other cancers, 
including gliomas. Elexpuru-Camiruaga et al. (1995) were the first to show that cytochrome p4502D 6 and glutathione transferase theta were significantly associated with an increased risk of brain tumor. Kelsey et al. (1997) found that glutathione transferase theta null genotype was associated only with an increased risk of oligodendroglioma. Trizna et al. (1998) found no statistically significant associations between the null genotypes of glutathione transferase mu, glutathione transferase theta, and CYP1A1 and risk of gliomas in adults, but observed a nearly 2 -fold increased risk for rapid $\mathrm{N}$-acetyltransferase acetylation and a $30 \%$ increased risk for intermediate acetylation. However, that finding was not confirmed in another case-control study of adults with glioma (Peters et al., 2001).

Chen et al. (2000) showed that patients with oligoastrocytoma were 4.6 times (95\% CI 1.6-13.2) as likely as controls to have AA or AC versus CC genotype in nucleotide 8092 of ERCC1, but the OR of those genotypes was about the same in patients with glioblastoma and controls. Although this variant is a silent polymorphism (does not lead to an amino acid change), it might affect ERCC1 mRNA stability, and the same polymorphism leads to an amino acid substitution of lysine to glutamine in a nucleolar protein and T-cell receptor complex subunit. Using the same populations as those reported by Chen et al. (2000), Caggana et al. (2001) found the AA genotype (C to A polymorphism [R156R]) of ERCC2 to be statistically significantly more common than the CC or CA genotypes in patients with glioblastoma, astrocytoma, or oligoastrocytoma than in controls. This variant is also a silent polymorphism, suggesting that another gene linked to it, but not this one, may account for the associations observed. Moreover, as genotyping data from blood tests were not available for those patients with the poorest survival in this population-based study of gliomas, it is not certain whether these polymorphisms were related to survival or to etiology. Further work is clearly warranted to confirm or refute these provocative findings. Larger studies may be needed, as chance can play a role in falsely identifying or failing to identify associations, especially when sample sizes are small.

\section{Mutagen Sensitivity}

Bondy et al. $(1996,2001)$ have shown that lymphocyte mutagen sensitivity to gamma radiation is significantly associated with a risk of glioma. A predisposition to cancer and capability for DNA repair are related to cellular sensitivity to radiation, both in vitro and in vivo. Although the relation of glioma development and mutagen sensitivity to radiation requires further study, it may be that people sensitive to gamma radiation are at an increased risk for developing brain tumors. It is doubtful that any one polymorphism will prove to be the prognostic marker for all brain tumors. Other forms of mutagen sensitivity also might be important in brain tumor susceptibility (Shadan and Koziol, 2000). On that basis, efforts to establish the relation of genetic polymorphisms to the development of brain tumors at present are focused on developing panels of possibly relevant polymorphic genes to integrate with epidemiologic data.

\section{Noninherited Endogenous, Infectious, and Environmental Risk Factors}

Not all of the noninherited risk factors consistently associated with brain tumors are necessarily considered to cause brain tumors (Table 1). For example, as discussed in more detail below, epilepsy, seizures, and convulsions are generally thought to be symptoms rather than causes of brain tumors, and head injuries might lead to increased detection of brain tumors rather than to the brain tumors themselves. Furthermore, some factors have been studied extensively with little suggestion of any real role. Details about the many factors that may be associated with brain tumors are given in more exhaustive summaries by Inskip et al. (1995), Preston-Martin and Mack (1996), and Davis and Preston-Martin (1998). Because many studies of brain tumors have involved small numbers of cases, many reported associations have lacked statistical significance. The term "association" also does not connote causality.

\section{Prior Cancers}

Malmer et al. (2000) reported increased risk of meningioma among persons who had colorectal cancer $($ SIR $=1.6 ; 95 \%$ CI 1.3-1.9) and among women who had breast cancer (SIR $=1.6 ; 95 \%$ CI 1.4-1.8). Teppo et al. (2001) found that brain tumors were 3 times more common than expected among people with small-cell lung carcinoma and twice as frequent as expected among people with adenocarcinoma. Common environmental or susceptibility factors might explain these disease associations. Wrensch et al. (1997) found that nearly equal proportions of adults with glioma and controls reported having had a cancer previous to glioma diagnosis (cases) or before interview (controls) OR 1.0 (95\% CI 0.7-1.5).

\section{Infections}

Several types of viruses, including retroviruses, papovaviruses, and adenoviruses, cause brain tumors in experimental animals, but with the exception of studies of human immunodeficiency virus-related brain lymphomas (Gavin and Yogev, 1999; Taiwo, 2000), few epidemiologic studies have addressed the potential role of viruses in causing human brain malignancies.

Between 1955 and 1963, an unknown proportion of all inactivated and live polio vaccines distributed was contaminated with SV40 (Fisher et al., 1999). Investigations of the relation between SV40 and cancer risk have shown mixed results. In one case-control study, more children with medulloblastoma than controls had been exposed to SV40 in utero (Farwell et al., 1984). Among a very large cohort of German children evaluated over a 20-year follow-up period, those inoculated with polio vaccine contaminated with SV40 had a somewhat higher occurrence of glioblastoma, medulloblastoma, and some less common brain tumor types than did those not given contaminated vaccine (Geissler and Staneczek, 1988). A similar study in the U.S. showed no difference in the risk of brain tumor between people who received SV40contaminated vaccine as a child and those who did not 
(Strickler et al., 1998). However, a more recent study (Fisher et al., 1999) showed that the rate of ependymoma in the exposed cohort was $37 \%$ higher than that in the unexposed cohort.

The relation of exposure to chicken pox virus (varicella zoster virus) and the risk of brain tumors also has been examined. A study in Finland (Bithell et al., 1973) showed that more mothers of children with medulloblastoma than mothers of control children had chicken pox during pregnancy. Wrensch et al. (1997) found that in the San Francisco Bay Area, a statistically significantly smaller proportion of adults with glioma than controls reported having had either chicken pox or shingles. We corroborated this observation with serologic evidence indicating that cases were less likely than controls to have antibody to varicella zoster virus (Wrensch et al., 2001).

A study conducted in Greece showed an OR for childhood brain tumors of 3.15 (95\% CI 1.1-8.8) for the mother's exposure to influenza during the index pregnancy (Linos et al., 1998). However, there was no serologic confirmation, and the number of case and control mothers exposed to influenza was small (Fisher et al., 2000). Among 97 cases of adults with glioma and 112 controls in Michigan (Fisher et al., 2000), fewer cases had been treated for at least one cold or influenza infection during 2 to 5 years before diagnosis of the tumor than had controls during the same time period, but more cases than controls had received an influenza vaccination during that time.

Most studies show a low frequency of the JC and BK viruses in brain tumors (Davis and McCarthy, 2000; Inskip et al., 1995). JC virus - a polyoma virus similar to SV40 - induces brain tumors in experimental animals (Inskip et al., 1995) and infects more than $70 \%$ of the human population worldwide (Del Valle et al., 2001). JC viral sequences were detected in 11 of $23(47 \%)$ medulloblastoma specimens (Krynska et al., 1999). A recent study of several pathologic subtypes of brain tumor showed the presence of viral early sequences in $69 \%$ of 71 samples tested (Del Valle et al., 2001). Immunohistochemistry studies showed that $32.9 \%$ of 85 tumor samples tested contained JC virus T-antigen, which may be able to inactivate some tumor suppressor genes such as p53. One study (Cuomo et al., 2001) has shown the presence of human herpes virus 6 (HHV-6) DNA in 43 of 115 $(37 \%)$ neoplastic brain tissues and in 10 of $31(32 \%)$ normal brain samples. However, herpes virus 6 p41 antigen was detected in neoplastic but not in normal brain tissue, suggesting that herpes virus 6 may act as cofactor rather than having a direct role in brain tumor development. Much work is needed to decipher the role, if any, of these and other viruses in human brain tumorigenesis.

Among nonviral infectious agents, Toxoplasma gondii has been reported to cause gliomas in experimental animals (Berleur and Cordier, 1995; Wrensch et al., 1993). Although one epidemiologic study (Schuman et al., 1967) convincingly linked astrocytoma with antibodies to T. gondii, a more recent study showed no association with adult glioma, but did report an association with meningioma (Ryan et al., 1993).

\section{Allergies}

An international study of 1178 glioma and 331 meningioma cases and 2493 controls from France, Germany, Sweden, southeastern Australia, the western U.S., and eastern and south central Canada showed an inverse association (OR $0.6 ; 95 \%$ CI $0.5-0.7$ ) of allergic diseases (asthma, eczema, and other) with glioma but not with meningioma (Schlehofer et al., 1999). Various sources and designs were used to ascertain cases and controls matched for age and sex in the different sites, but all were to some degree population-based sources. Glioma caseversus-control ORs for history of any allergic disease were statistically significantly less than 1.0 at 4 study sites, were not statistically significantly less than 1.0 at 3 study sites, and were slightly greater than 1.0 at 1 study site (Sweden). In contrast, meningioma-versus-control ORs for any allergic disease were not significant at any of the study sites, being somewhat greater than 1.0 at 3 study sites, and somewhat less than 1.0 at 3 study sites.

Among 405 adults newly diagnosed with glioma from 1997 to 1999 in the San Francisco Bay Area and 402 population-based controls frequency matched for age, sex, and ethnicity, fewer patients than controls reported any allergy $(72 \%$ versus $85 \%)$, and the OR was 0.5 (95\% CI 0.3-0.7); for self-reported cases $(n=269)$, the OR was 0.7 (95\% CI 0.4-0.97); and for proxy-reported cases, the OR was 0.3 (95\% CI 0.2-0.5) (Wiemels et al., 2002). Allergies to pollen, dairy products, and nuts were reported by fewer patients (a statistically significant association) than controls and fewer patients than controls also reported allergies to several other allergens. There were no apparent trends with numbers or types of symptoms, severity of the allergy, or route of exposure to the allergen. However, there was a statistically significant inverse dose response of glioma with increasing numbers of allergens. A recent report on 489 glioma, 197 meningioma, and 96 acoustic neuroma cases and 7999 controls with nonmalignant conditions seen at hospitals from 3 U.S. cities also found history of any allergy to be inversely associated with glioma $(\mathrm{OR}=0.7 ; 95 \%$ CI 0.6-0.9) but not associated with either meningioma or acoustic neuroma (Brenner et al., 2002). This study also reported inverse associations of autoimmune diseases (especially asthma and diabetes) with both glioma and meningioma. The independent replication of the finding of an inverse association of history of allergies with glioma in 3 large well-conducted series that used a variety of study designs for ascertaining subjects suggests that further work to understand the basis of the observed relationship is warranted and might reveal a role for immunologic factors in glioma genesis. The possible role of allergy medications might also deserve further study.

\section{Trauma and Head Injury}

Head injury and head trauma have long been suspected to be related to some types of brain tumors. Epidemiologic studies have helped sort out which types of tumors are and are not likely to be associated with these conditions. Case-control studies that compared controls with adult glioma patients who had a history of head injury 
requiring medical attention found no evidence of an association (ORs range from 0.7 to 1.3; Wrensch et al., $2000 \mathrm{~b})$. Somewhat higher relative risks have been reported when any head injuries are considered (Ahlbom et al., 1986; Burch et al., 1987; Choi et al., 1970; Codd et al., 1990; Preston-Martin et al., 1989; Ryan et al., 1992; Schlehofer et al., 1992), suggesting the possibility that cases may have been more likely to recall minor head injuries than controls. There has been more evidence of a possible link between head injuries and meningiomas or other brain tumors, such as acoustic neuromas (Inskip et al., 1995, Preston-Martin and Mack, 1996), but casecontrol reporting differences might explain the findings. To overcome this reporting problem, Inskip and colleagues undertook a large cohort study of incidence of i.c. tumors after hospitalization for head injuries in Denmark (Inskip et al., 1998). There was no increased risk of glioma or meningioma during an average of 8 years of follow-up review, except during the first year. The authors suggested that the increased incidence during the first year after the injury could have been due to increased early detection, but they did not observe a concomitant decrease in cases in subsequent years. In an international study of 1178 adults with glioma, 330 with meningioma, and 2236 controls, Preston-Martin et al. (1998) reported elevated ORs for meningioma in men with prior head injury, especially among those with a 15- to 24-year latency. The investigators found no or minimal association of head injury with meningioma in women or with glioma in either men or women. Some investigations have found that, compared with control children, more children with brain tumors have been reported to have had a birth trauma or other head injury (Gurney et al., 1996); however, recall bias may have been a factor accounting for some of the reports.

\section{Seizures}

Patients with glioma are more likely than controls to report having had epilepsy or seizures, even many years before the tumor is diagnosed (Ryan et al., 1992; Wrensch et al., 1997). Although more patients with epilepsy develop brain tumors than would normally be expected (Clemmesen and Hjalgrim-Jensen, 1978; Olsen et al., 1989; Shirts et al., 1986; White et al., 1979), determination of causality is problematic because seizures are often a symptom of brain tumors that leads to diagnosis (Lote et al., 1998). Pace et al. (1998) showed that $83 \%$ of patients with astrocytoma, $46 \%$ with anaplastic astrocytoma, and $36 \%$ with glioblastoma had seizures preoperatively. Even if seizures occured several years before diagnosis of a brain tumor, it would be difficult to determine whether the seizures or the medications controlling the seizures contributed to tumor risk.

\section{Drugs and Medications}

Few studies have investigated the association of drugs and medications with the risk of brain tumors (Preston-Martin and Mack, 1996). Few statistically significant or consistent findings have been observed in studies of brain tumor development in relation to prenatal exposure to fertility drugs, oral contraceptives, sleeping pills or tranquilizers, pain medications, barbiturates, antihistamines, neuroactive drugs, or diuretics. Also, no strong associations between headache, sleep, and pain medications have been reported with respect to adult brain tumors, and the reported associations were not statistically significant.

\section{Other Medical Treatments and Conditions}

Brinton et al. (2001) reported a rather surprising finding that women who received breast implants had a significantly elevated risk of brain cancer. Leukemia was also more frequent than expected in the cohort, and the authors had no obvious explanations for this intriguing finding. McCredie et al. (1999), reporting on a variety of birth characteristics, found only use of anesthetic gas during delivery to be associated with childhood brain tumors. Strauss et al. (1999) reported a very high risk of brain tumor mortality among people with cerebral palsy.

\section{Diet and Vitamins}

$N$-nitroso compounds have been identified as neurocarcinogenic in experimental animals. Animal studies have pointed mainly to nitrosamides rather than nitrosamines in neurocarcinogenesis. Parents' exposure to these compounds as well as perinatal exposure may cause DNA damage that might play a role in human brain tumor development (see Berleur and Cordier, 1995; PrestonMartin and Mack, 1996). Fetal exposure produces more tumors in animals than does postnatal exposure. Because tumor development may become evident only long after exposure, it is conceivable that adult tumors could result from prenatal or early postnatal exposure. Assessing exposure to $\mathrm{N}$-nitroso compounds is difficult because they are extremely common in both endogenous and exogenous sources, including food. Vegetables that are high in nitrites also contain vitamins that may block the formation of $\mathrm{N}$-nitroso compounds. Amino acids broken down from some food sources may be converted to $\mathrm{N}$-nitroso compounds by a nitrosating agent, such as nitrites from cured meats.

Oxidants and antioxidants also have a role in causing cancers and other degenerative diseases of aging (Ames et al., 1993). Oxidants damage DNA in a cumulative manner, and the damage is less readily repaired with age. They derive from endogenous sources that include normal aerobic respiration, nitric oxide produced when cells fight infections, and oxidative by-products of the cytochrome p450 2D6 detoxification enzymes. Exogenous sources, which are many and varied, include certain foods, iron, and oxides of nitrogen in tobacco smoke. Antioxidants-chemicals that remove or lower the concentration of oxidants - may minimize DNA or cellular damage or may enhance DNA repair. Sources of antioxidants include diets high in fruits and vegetables, antioxidant vitamin supplements, and many endogenous processes and enzymes. 
Epidemiologic studies of diet and vitamin supplementation have provided mixed support for the hypothesis that dietary $\mathrm{N}$-nitroso compounds, antioxidants, or specific nutrients might influence the risk of either childhood or adult brain tumors, as reviewed in a number of reports (Berleur and Cordier, 1995; PrestonMartin and Mack, 1996; Wrensch et al., 1993), including some published more recently (Blot et al., 1999; Hu et al., 1999; Kaplan et al., 1997; Lee et al., 1997; Lubin et al., 2000; Tedeschi-Blok et al., 2001). In a review of the relationship between childhood cancer and cured meat in the diet, Blot et al. (1999) observed that most studies found no statistically significant association between the mother's total consumption of cured meat during the index pregnancy and the risk for developing a brain tumor in the child, but more studies found positive rather than negative relationships. There was little consistency in the relationship when individual cured meats were investigated. Lubin et al. (2000) observed no association of mother's nitrate, nitrite, or vitamin C intake during gestation and risk for a brain tumor in the child. However, children with brain tumors had higher consumption of vegetable fat than did controls $(\mathrm{OR}=1.4 ; 95 \%$ CI 1.1-1.7), and their mothers had consumed more potassium during gestation than had control mothers (OR $=1.4 ; 95 \%$ CI 1.0-2.0). Lee et al. (1997) found that, compared with healthy controls, adults - particularly men - who had a glioma consumed a diet higher in cured foods and nitrites and lower in vitamin C-rich fruits and vegetables. Hu et al. (1999) observed that, in northeastern China, brain tumor patients were less likely than controls to report consumption of fruit, soybean products, lard, poultry, fresh fish, and salted vegetables and had lower estimated intake of vitamin $\mathrm{E}$ and calcium. Unfortunately, the study analyses combined patients who had meningioma with those who had glioma. In the San Francisco Bay Area, Tedeschi-Blok et al. (2001) also observed that women, but not men, with glioma had lower estimated calcium intake (a statistically significant association) than did controls.

\section{Smoking}

Although some carcinogenic components of tobacco smoke cannot penetrate the blood-brain barrier, $N$-nitroso compounds can, and it has been hypothesized that they may be involved in the development of some brain tumors. However, both a meta-analysis and a review (Boffetta et al., 2000; Norman et al., 1996) found no clear association between a mother's smoking tobacco during pregnancy and risk for a brain tumor in the child. An only slightly higher median relative risk was associated with passive smoking exposures to the child or his or her mother. The results from exposure to passive smoking by the father suggested a slightly increased relative risk of 1.2 (95\% CI 1.1-1.4) based on 10 studies (Boffetta et al., 2000). Results of studies of adults suggest no important contribution of tobacco smoking to risk of a brain tumor, although Lee et al. (1997) and Burch et al. (1987) showed increased risk of adult glioma with smoking unfiltered, but not filtered, cigarettes.

\section{Alcohol}

Alcohol consumption by the mother appears to have only a slight association, if any, with the risk for childhood brain tumors (Preston-Martin and Mack, 1996; Wrensch et al., 1993). Of 3 studies, 2 showed a positive effect, with a median risk of about $40 \%$ among offspring prenatally exposed to alcohol, but in only 1 of these studies was the finding statistically significant. In China, Hu et al. $(1999,2000)$ found that a greater proportion of fathers whose children were born with a brain tumor reported consuming hard liquor before the child's conception than did fathers of control children. In another recent study from China, adults with meningioma or glioma were more likely than controls to report consumption of beer or other liquor (Hu et al., 1999). In aggregate, however, the results for adults suggest no increased, and possibly a decreased, risk for glioma with the consumption of beer and wine. In a previous review by Wrensch et al. (1993), 4 of 8 studies cited relative risks of less than 1 for any versus no alcohol use.

\section{Personal and Residential Chemical Exposures}

A study done in Canada showed that more adults with brain tumors than controls reported use of hair dyes and hair sprays (Burch et al., 1987). Collectively, studies evaluating the mother's exposure to cosmetics that contain $\mathrm{N}$-nitroso compounds have not shown a positive association with a risk of childhood brain tumors (Preston-Martin and Mack, 1996).

Studies of residential chemical exposures have focused mainly on the relationship between prenatal and postnatal exposures to pesticide and pediatric brain tumors (Preston-Martin and Mack, 1996). The associations of pesticide exposures and the risk of childhood brain cancers have been recently summarized by Zahm et al. (1999); 9 studies reported a statistically significant increased risk of brain tumors and pesticide exposure; 5 studies showed nonstatistically significant elevated risk; and 3 showed no associations. These results combine studies that considered both prenatal and childhood exposures. Presumptive pesticide exposures included the mother using household insecticides or pesticides, the father engaging in agricultural work, and the child having contact with pets. Recall bias and reporting bias of statistically significant studies are important caveats to consider in evaluating these associations. Pogoda and Preston-Martin (1997), in a large population-based study, found a significantly increased risk of pediatric brain tumors associated with prenatal exposures to flea and tick pesticides. Because other pesticide exposures were not associated, the authors thought that recall bias by the mothers of children with brain tumors was not likely to account for the link to flea and tick products.

A traffic-related air pollution study that used benzene and nitrogen dioxide concentration as markers of air pollution found no association between traffic density or exposure to air pollutants and a risk of developing a childhood brain tumor (Raaschou-Nielsen et al., 2001). With regard to drinking water, in Iowa, men with glioma were more likely than controls to have drinking water 
from chlorinated sources (a statistically significant association); similar results were not found for women (Cantor et al., 1999).

\section{Industry and Occupation}

Associations between exposure to specific occupational or industrial chemicals and the development of human brain tumors have been difficult to establish. A comprehensive review of occupational risk factors for brain tumors was published in 1986 (Thomas and Waxweiler, 1986), and despite the many studies done since, most of the same issues remain relevant.

In many occupations and industries, workers are exposed to neurotoxic or carcinogenic substances, or both, in the form of lubricating oils, organic solvents, formaldehyde, acrylonitrile, phenols and phenolic compounds, and polycyclic aromatic hydrocarbons. Some of those chemicals induce brain tumors in experimental animals. Studies of animals, most of them rats, show that the strain, the gestational age, and the fetal versus adult status significantly influence susceptibility to tumor development. These are factors that often cannot be accounted for or generalized to occupational cohort exposure studies. For example, brain tumors are induced in animals by some compounds, such as polycyclic aromatic hydrocarbons, only through direct implantation, or transplacentally, and are not generally induced through the inhalation or dermal exposures most relevant to occupational groups. Moreover, workers are seldom exposed simply to one chemical, and chemicals may well interact with other chemicals to increase or reduce risk. Even in the largest occupational cohort studies, the number of brain tumor cases is often too small to permit meaningful subgroup analyses to detect damaging chemicals, physical agents, work processes, or interactions.

For these reasons, no definitive association of brain tumors with specific chemicals has been established, even for known or putative carcinogens. Some pesticides and other agricultural chemicals, such as organochlorides and alkylureas combined with copper sulfates, have been suspected because they induce cancer in experiments with animals. According to a review by Bohnen and Kurland (1995), however, case-control studies and cohort studies of agricultural workers have produced negative or positive findings about equally often with regard to the risk for brain tumors. In the meta-analysis of brain malignancies and farming by Khuder et al. (1998), the 33 studies yielded a relative risk of 1.3 (95\% CI 1.1-1.6). Although studies of workers in pesticide or fertilizer manufacturing have not shown an unusual risk of brain tumors, 4 of 5 studies of pesticide applicators have shown an increased risk of brain tumors with a nearly 3 -fold median relative risk (Bohnen and Kurland, 1995). In an occupational study of women in the U.S., insecticide and fungicide exposure was associated with a small but statistically significant increased risk for brain tumors (OR 1.3; 95\% CI 1.1-1.5) (Cocco et al., 1999). A recent study reported a positive association between wheat-producing acreage and brain tumor mortality in Minnesota, Montana, and the Dakotas, suggesting a possible role of chlorophenoxy herbicides employed in wheat agriculture (Schreinemachers, 2000).
The median relative risk of brain tumors found in studies of workers engaged in the production and processing of synthetic rubber was 1.9 (Thomas and Waxweiler, 1986; Weiland et al., 1996). A recent study also showed increased risks (Straif et al., 2000). In this industry, there may be a causal connection to the risk of brain tumors because by-products of synthetic rubber production, such as coal tars, carbon tetrachloride, $\mathrm{N}$-nitroso compounds, and carbon disulfide, are thought to be carcinogenic. Nonetheless, the results have been inconsistent.

Studies conducted in rats have shown that brain tumors can be induced by vinyl chloride. Nine of 11 studies of workers involved in polyvinyl chloride production have shown increased relative risks of dying from brain tumors, with about a 2-fold median relative risk (Hagmar et al., 1990; Thomas and Waxweiler, 1986; Wong et al., 1991; Wu et al., 1989). A recent review of the association between vinyl chloride and cancers indicated that the role of vinyl chloride in the development of brain tumors is still inconclusive (McLaughlin and Lipworth, 1999). A large cohort study supports this notion, stating that mortality from brain cancer has attenuated, but the role of vinyl chloride is still unclear (Mundt et al., 2000). Using exposure ranking as a proxy for actual dose showed no association between vinyl chloride exposure and brain cancer (Lewis, 2001). Another study also did not demonstrate a relationship of brain tumors to extent of vinyl chloride exposure (Simonato et al., 1991). However, in reviews of animal studies that indicated neurocarcinogenicity of vinyl chloride, there have been difficulties in determining whether the tumors were primary or metastatic (Rice and Wilbourn, 2000). Given this concern, future plans for trying to understand the role, if any, of vinyl chloride in causing human brain tumors need to include reconsideration of the biologic plausibility of the association and perhaps to consider more definitive animal studies.

Embalmers, pathologists, anatomists, and other professionals exposed to formaldehyde appear to be at increased risk of brain tumors, but such increased risks were not observed for industrial workers with presumed exposure (Blair et al., 1990). Although formaldehyde is not considered an agent of human brain tumorigenesis on that basis, other cofactors might obscure actual risk in occupationally exposed workers and could create the impression of increased risk in the exposed professional groups (Thomas and Waxweiler, 1986).

The question of whether petrochemical, petroleum, and oil production industry workers are at higher risk for brain tumors is unresolved. More than 20 years of research in this area has failed to yield conclusive answers, although accumulated evidence suggests that a cautious admission of the relationship between certain parts of the petrochemical industry and increased risk is in order. Suspected clusters of brain tumors were reported in several Texas petrochemical plants in the 1970s. The Texas mortality study was recently updated (Divine et al., 1999) and continued to show excess risk of brain tumor in certain occupations. Updates of studies of crude U.S. oil production workers found a slightly increased risk of brain tumors (Divine and Hartman, 2000), and a very large meta-analysis found no overall increased brain cancer 
mortality in petroleum workers (Wong and Raabe, 2000). The preponderance of studies of workers in petrochemical production and oil refineries have shown increased risks of brain tumor mortality of $20 \%$ to $80 \%$ (Cooper et al., 1997; Preston-Martin and Mack, 1996; Wrensch et al., 1993). A recent study showed an increased risk (OR 4.9; 95\% CI 0.6-42.2) for glioma among petroleum and gas workers in the San Francisco Bay Area (Carozza et al., 2000). Two recent studies of a suspected brain tumor cluster in a petrochemical research facility found an excess of benign brain tumors, but a deficit of brain cancer deaths (Delzell et al., 1999; Rodu et al., 2001; Sathiakumar et al., 2001). Although there appears to be a trend toward increased risk among workers in some parts of the petrochemical industry, the lack of detection of a responsible agent in more detailed studies confounds a causal connection. However, it may be that multiple exposures contribute to the risk.

Scientists and biomedical professionals have also been examined for brain tumor risk. Although patients with glioma in the San Francisco Bay Area were more likely than controls to be physicians and surgeons (OR 3.5; 95\% CI 0.7-17.6; Carozza et al., 2000), no specific medical specialty was singled out as being at increased risk for brain tumors, and the results are compatible with chance. It is possible that physicians were less likely to participate as controls in that study. A study of a small number of cases in Sweden showed that the SIR was slightly elevated for male scientists (SIR 2.26), but no brain tumor cases were observed among scientists not working in a laboratory (Wennborg et al., 1999). In a study of clinical laboratory technicians, radiologic technicians, and science technicians, the proportionate cancer mortality ratios for brain tumors were not elevated (Burnett et al., 1999), but another study did find nonsignificantly elevated risks among biologic laboratory workers (Rachet et al., 2000). Among men registered with the Brazilian Navy Insurance, those who were health personnel showed an OR for malignant brain tumor of 2.3 (95\% CI 1.1-5.0) (Santana et al., 1999).

Brain tumor risks among firefighters have been the subject of several studies (Aronson et al., 1994; Demers et al., 1991, 1992, 1994; Deschamps et al., 1995; Firth et al., 1996; Golden et al., 1995; Guidotti, 1995; Ma et al., 1998; Moen and Ovrebo, 1997; Tornling et al., 1994; Vena and Fiedler, 1987). Although there is a possible association, definitive conclusions have been limited by studies with small numbers of cases and concomitant difficulties demonstrating increased risk with increased numbers of years as a firefighter or with numbers or types of fires fought.

Carozza et al. (2000) observed an increased OR for glioma among artists in the San Francisco Bay Area (OR 1.9; 95\% CI 0.5-0.6). Legal and social service workers, shippers, janitors, motor vehicle operators, and aircraft operators also had increased ORs in that study, but only with a long duration of employment. In a study of women, actors and directors appeared to have elevated proportionate mortality rates for brain and CNS tumors (Robinson and Walker, 1999).

A population-based study of 375 malignant brain tumor cases and 2434 controls in Iowa found statistically significant associations for 10 occupations and 11 industries among men and for 7 occupations and 6 industries among women (Zheng et al., 2001). The occupations for men included clergy, commodities salespersons, guards, cleaning and building service, janitors and cleaners, miscellaneous mechanics and repairers, construction and extractive occupation supervisors, material moving equipment operators, military occupation, and other financial officers. For women, the occupations included retail sales supervisors, retail sales occupations, commodities salespersons, record clerks, waitresses, farm occupations, and general farm workers. The industries for men included plumbing, heating and air conditioning, roofing, siding, sheet metalwork, newspapers, rubber and plastic products, tires and inner tubes, miscellaneous manufacturing industries, electrical service, wholesale trade of durable goods, wholesale trade of farm products, wholesale trade of field beans, and gasoline service stations. For women, the industries included agriculture, apparel and other textile products, electrical and electronic equipment, department stores, miscellaneous retail and drug stores, and proprietary industries.

\section{Brain Tumor Clusters in Occupational or Residential Settings}

Reports of brain tumors apparently arising in clusters of people in an occupational or residential setting have often raised concern. Investigations of brain tumor clusters can be time-consuming and are often inconclusive because of disease heterogeneity and unknown or inadequately characterized exposures, latency periods, and/or base populations. We do not review the evidence for/against any such cluster here. Davis et al. (1999a) provide some information for computing expected numbers of cases. The Centers for Disease Control (CDC, 1990) also provides guidance in evaluating disease clusters.

\section{Parents' Workplace Exposures}

It is possible that parents' exposure to carcinogens in the workplace could increase the risk of cancer in their children. A father's exposures before conception might damage his DNA, and a mother's exposures might have a direct impact on the developing fetus. Parents' workplace exposure to infectious agents could be transmitted to the child, and children could be exposed to chemical carcinogens that might remain on a parent's skin or clothing. However, there is no definitive evidence of such exposures causing brain tumors. Limitations in studies include small population sizes, multiple or rare exposures, confounding factors, and insufficient follow-up data. Wrensch et al. (1993) reviewed 16 studies published before 1993 concerning the relation of parents' occupations and childhood brain tumors. They found that significantly elevated risks of childhood brain tumors were reported for fathers working with, or working in, industries involving paper and pulp, solvents, painting, printing and graphic arts, oil or chemical refining, farming, metallurgy, and air and space. Nonetheless, there have also been reports of negative findings among employees in aerospace industries, 
and several studies of parents' working with hydrocarbons have shown no associations with risk of childhood brain tumors. A few positive studies relating an increased risk of childhood brain tumors with mothers' prenatal or postnatal exposures are contradicted by several other studies showing no such relation. No conclusions can be drawn from those studies because of a lack of specificity about the exposures in the positive studies and an insufficient sample of exposed mothers in the negative studies.

A recent Norwegian study (Kristensen et al., 1996) showed a significantly elevated incidence of brain tumors $(60 \%)$ in children whose parents were pig farmers, but nonsignificant elevations for parents working in chicken farming, grain farming, horticulture, or other jobs involving pesticide use. The results were stronger for children who probably grew up on a farm as well as having parental exposure and were also stronger for nonastrocytic neuroepithelial tumors (choroid plexus papillomas, ependymomas, oligodendrogliomas, medulloblastomas, gangliogliomas, and neuroblastomas) than for astrocytomas. Holly et al. (1998) reported elevated risks of childhood brain tumors associated with maternal exposures during pregnancy to pigs, horses, or poultry on a farm.

\section{Ionizing Radiation}

Therapeutic ionizing radiation is a strong risk factor for brain tumors (Hodges et al., 1992; Preston-Martin and Mack, 1996; Socie et al., 2000; Wrensch et al., 1993). Relatively low doses of radiation used to treat tinea capitis and skin hemangioma in children or infants have been associated with relative risks of 18 for nerve sheath tumors, 10 for meningiomas, and 3 for gliomas (reviewed in Preston-Martin and Mack, 1996; Karlsson et al., 1998). Radiation for treatment of the nasopharynx for adenoid hypertrophy was associated with a very large though not statistically significant relative risk of 14.8 (95\% CI $0.8-286.3$; Yeh et al., 2001).

One study showed a high prevalence $(17 \%)$ of prior therapeutic irradiation among patients with glioblastoma (Hodges et al., 1992), and another reported an increased risk of glioma or other brain tumors in patients who had undergone irradiation for acute lymphoblastic leukemia as children (Salvati et al., 1991; Shapiro et al., 1989). An elevated risk of subsequent primary or recurrent brain tumor has also been observed after radiation therapy for childhood cancer other than leukemia (Little et al., 1998; Loning et al., 2000). Neglia et al. (1991) reported a relative risk for CNS tumors of 21.7 (23 tumors observed versus 1.1 expected; $P<0.05$; no CI given) among children treated with irradiation for acute lymphoblastic leukemia. Second primary brain tumors also occur more frequently than expected especially among patients treated with radiotherapy (Salminen et al., 1999).

A study of survivors of the atomic bombing of Hiroshima showed a high incidence of meningioma correlating with the dose of radiation to the brain (Shintani et al., 1999). The incidence increased with closer distance to the hypocenter. The role of prenatal exposure is unclear. Japanese studies of atomic bomb survivors have not shown an increased risk of brain tumors among those who were exposed in utero (Preston-Martin and Mack, 1996), whereas some studies have shown a $20 \%$ to $60 \%$ increased risk of childhood brain tumors due to prenatal exposure to radiation. Parents' exposure to ionizing radiation before conception of the affected child has not been shown to be associated with an increased risk of childhood brain tumors (Preston-Martin and Mack, 1996).

Diagnostic radiation techniques have not been associated with an increased risk of glioma. The San Francisco Bay Area Adult Glioma Study showed that neither nondental diagnostic X-rays focused to the head and neck nor dental visits and procedures contributed to the risk of developing a glioma (Wrensch et al., 2000b). For meningioma, 3 studies showed a greater than 2 -fold increased risk after exposure to dental X-rays (Preston-Martin and Mack, 1996), and the studies showed a stronger effect for X-rays taken in the more distant past, suggesting either that there was a latency period or that exposures may have been higher in the past.

Nuclear facility employees and nuclear material production workers may have an elevated relative risk of 1.2 (95\% CI 0.8-2.0) for brain tumors (Loomis and Wolf, 1996), but confounding or effect modification by chemical exposures makes interpretation of causality difficult. A large cohort of U.S. nuclear workers was recently reexamined and again shown to have about $15 \%$ increased risk of brain tumors (Alexander and DiMarco, 2001). There is no consensus about the risk of malignant brain tumor among pilots, although some believe that exposure to cosmic radiation at high altitudes may contribute to a brain tumor risk (Gundestrup and Storm, 1999; Wrensch et al., 1993). However, a recent study of British Airway flight deck workers did not show statistically significant mortality from brain tumors (Irvine and Davies, 1999).

\section{Cellular Telephones and Radio Frequency EMFs}

Concern over possible health effects of using cellular telephones has prompted studies looking at the relation between cell-phone usage and an increased risk of brain tumors. Two case-control studies and a cohort study suggest that there is no association. Muscat et al. (2000) observed no association between duration of cell-phone use and brain tumor incidence. Moreover, no brain tumor site or histology was associated with the use of handheld cell phones (Muscat et al., 2000). However, the authors noted that the brain tumors most often occurred on the same side of the head as the ear used for the cell phone (Muscat et al., 2000). Inskip et al. (2001) showed that the relative risks of any use of a cell phone was $1.0(95 \%$ CI 0.7 1.4) for patients with glioma, 0.8 (95\% CI 0.5-1.2) for those with meningioma, and 0.8 (95\% CI $0.5-1.4$ ) for those with acoustic neuroma. The relative risk did not increase with increased duration of cell-phone use or increased cumulative hours used. An earlier study also showed no association between cell-phone use and brain tumors (Hardell et al., 1999). In a cohort study in Denmark, Johansen et al. (2001) observed no excesses of brain or CNS cancers due to cell-phone usage. One recent case-control study suggested an increased risk of brain tumor on the same side of 
usual phone use (Hardell et al., 2001), reporting an OR of 2.4 (95\% CI 0.97-6.0) for ipsilateral cellphone use for temporal, temporal-parietal, and occipital areas of the brain. But the finding was based on only 13 cases, and there was no association for ipsilateral phone use with tumors of the frontal, parietofrontal, parietal, or parietal-occipital areas or for brain hemisphere.

With the expanding prevalence of wireless communication technologies, radio frequency exposure is an important concern. Analog cellular telephone radio frequency signals operate in the range of 800 to $900 \mathrm{MHz}$, whereas newer digital phones operate in the range of 1600 to $2000 \mathrm{MHz}$ (Morgan et al., 2000). In a mortality study of employees of Motorola, a manufacturer of wireless communications products, there was no association between occupational radio frequency exposure and occurrence of brain malignancies (Morgan et al., 2000). Krewski et al. (2001) summarize recent research on the effects on health of radio frequency fields.

Although current reports show no apparent association between cell-phone usage and brain tumors, it may be important to continue study in this area because cellphone usage is becoming increasingly common. Many studies were conducted during a time when analog phones were the predominant type of cell phone, compared with digital phones today. Total duration of phone use was lower, and the number of cell-phone users was smaller. Moreover, long-term studies are probably needed because some brain tumors may take a long time to develop.

\section{Power Frequency EMFs}

The potential health effects of power frequency $(50-60 \mathrm{~Hz})$ EMFs have received substantial public and scientific attention. The interest arises from residential studies showing increased risk of brain tumors and leukemia in children whose homes have high EMF exposures. Occupational studies also have shown that presumably exposed workers have higher incidence and mortality rates associated with brain tumor. Recent meta-analyses of occupational studies suggest a statistically significant increased risk of $10 \%$ to $20 \%$ for brain malignancy among electrical workers (Kheifets et al., 1995; NIEHS, 1999). Three recent occupational studies reported an association among EMF-exposed workers (Minder and Pfluger, 2001; Robinson et al., 1999; Savitz et al., 2000), and others did not (Floderus et al., 1999; Johansen and Olsen, 1999). Studies have not found an association between maternal EMF exposure and brain tumors in their children (Feychting et al., 2000; Sorahan et al., 1999). Although one meta-analysis has shown a nonsignificant $50 \%$ increased risk of brain tumors for children living in high as opposed to low wire-coded homes (Meinert and Michaelis, 1996), a comprehensive assessment of childhood brain tumors in relation to residential EMF concluded that the evidence did not support an association (Kheifets et al., 1999). Although there is no proof that EMF does not influence the risk of brain tumors, no causal connection has been established. Methodologic and conceptual issues of equivalency make it especially difficult (and perhaps impossible) to prove the existence of no association between power-frequency EMFs and brain tumors. A definitive resolution to the question of whether EMF exposure causes brain tumors remains elusive for this and a variety of other reasons, as discussed by us (Wrensch et al., 2000a) and others (Blettner and Schlehofer, 1999; NIEHS, 1999; Wrensch et al., 1999). A primary reason given against a causal relation between EMF exposures and brain or other tumors is lack of convincing biologic plausibility of effect. However, 2 recently published studies suggest that residential EMF exposures may depress the normal levels of nocturnal melatonin production, and melatonin is thought to have oncostatic effects (Davis et al., 2001; Levallois et al., 2001).

\section{Directions for Future Studies}

Primary malignant brain tumors clearly represent a heterogeneous group of diseases. Therefore, a workable consensus on classification and increased use of molecular tumor markers in concert with improved surveillance and registration are necessary to characterize homogeneous subgroups of the many heterogeneous categories of primary brain tumors. For example, the recently elucidated distinction between "de novo" and "progressive" glioblastomas has significant implications for epidemiologic research (Kleihues and Ohgaki, 2000). This concept and others reinforce the notion that GBM is not one but probably many diseases that must be distinguished if progress is to be made in determining etiology. Molecular characterization of tumors may help to disentangle causes of subtypes of glioma by enabling researchers to group tumors with similar molecular lesions. Use of rapidly developing technology to examine arrays of either gene or protein expression (if it can be applied to paraffin-preserved tissue, so that large numbers of samples from epidemiologically well-characterized series can be studied) may help to categorize tumors into more homogeneous groups with regard to lesions of etiologic or prognostic importance. A major challenge to interpreting this information (as with information about tumor markers obtained from more conventional methods) will be deciphering which alterations represent early changes of potential etiologic significance and which represent later changes that may have serious prognostic consequences. Genetic and molecular epidemiologic methods to collect and define pertinent subject data from well-defined source populations and to follow up on subjects for recurrence and survival might help to make sense of the complex information about tumor molecular alterations.

The descriptive epidemiology of brain tumors suggests that a major unaccomplished task is to formulate and evaluate explanations for the consistently observed sex and ethnic differences for glioma and meningioma. Among the most provocative clues to the etiology of primary brain tumors in adults is the characteristic sex difference, with gliomas being more prevalent among men and meningiomas among women. The glaring absence of analytic epidemiologic research into risk factors for meningioma (Bondy and Ligon, 1996) provides little information to hypothesize reasons for the female preponderance other than the probable importance of hormonal factors. Furthermore, very few studies of glioma 
have shed any light on sex and ethnic differences in occurrence of these tumors, despite the extensive research of gliomas (Chen et al., 2001; McKinley et al., 2000).

Further analytic studies of environmental factors (viruses, radiation, and carcinogenic or protective chemical exposures through diet, workplace, or other sources), when combined with incorporation of potentially relevant polymorphisms that might influence susceptibility, may help us understand this devastating collection of diseases. Multicenter studies or sharing of data between ongoing studies might be needed to obtain sufficient numbers of cases to compare subgroups of subjects with specific molecularly defined tumor types. Studies of potentially relevant polymorphisms, viral factors, other infectious agents and immunologic factors are promising understudied areas for further etiologic research. Moreover, because currently established or suggested risk factors probably account for a small proportion of cases, novel concepts of neurocarcinogenesis may be required before we are able to discover a more comprehensive picture of the natural history and pathogenesis of brain tumors. With the rapid pace of discovery of meaningful tumor markers and susceptibility genes, this is an ideal time for neurosurgeons, oncologists, pathologists, and epidemiologists to forge new collaborations within and between their institutions and for professional organizations to design and conduct meaningful epidemiologic research into the causes of primary brain tumors.

To conclude, primary brain tumors probably stem from multiple exogenous and endogenous events. To date, the few proven causes (inherited genetic syndromes, therapeutic ionizing radiation, and immunosuppression giving rise to brain lymphomas) account for only a small proportion of cases. Brain malignancies are devastating diseases, but there is hope that with continuing explication of their cause and biologic course, new concepts about neuro-oncogenesis might emerge to advance the study of brain tumor epidemiology and to make prevention and cure possible.

\section{Acknowledgments}

Many thanks to Susan Eastwood and Pam Derish for editing the manuscript.

\section{References}

ACS (American Cancer Society). (1998) Cancer Facts and Figures 1998. Atlanta: American Cancer Society.

Ahlbom, A., Navier, I.L., Norell, S., Olin, R., and Spannare, B. (1986) Nonoccupational risk indicators for astrocytomas in adults. Am. J. Epidemiol. 124, 334-337.

Aldape, K., Simmons, M.L., Davis, R.L., Miike, R., Wiencke, J., Barger, G., Lee, M., Chen, P., and Wrensch, M. (2000) Discrepancies in diagnoses of neuroepithelial neoplasms: The San Francisco Bay Area Adult Glioma Study. Cancer 88, 2342-2349.

Alexander, V., and DiMarco, J.H. (2001) Reappraisal of brain tumor risk among U.S. nuclear workers: A 10-year review. Occup. Med. 16, 289-315.

Ames, B.N., Shigenaga, M.K., and Hagen, T.M. (1993) Oxidants, antioxidants, and the degenerative diseases of aging. Proc. Natl. Acad. Sci. U.S.A. $\mathbf{9 0 ,}$ 7915-7922.

Aronson, K.J., Tomlinson, G.A., and Smith, L. (1994) Mortality among fire fighters in metropolitan Toronto. Am. J. Ind. Med. 26, 89-101.

Berleur, M.P., and Cordier, S. (1995) The role of chemical, physical, or viral exposures and health factors in neurocarcinogenesis: Implications for epidemiologic studies of brain tumors. Cancer Causes Control 6, 240-256.

Bithell, J.F., Draper, G.J., and Gorbach, P.D. (1973) Association between malignant disease in children and maternal virus infections. Br. Med. J. 1, 706-708

Blair, A., Saracci, R., Stewart, P.A., Hayes, R.B., and Shy, C. (1990) Epidemiologic evidence on the relationship between formaldehyde exposure and cancer. Scand. J. Work Environ. Health 16, 381-393.

Blettner, M., and Schlehofer, B. (1999) Is there an increased risk of leukemia, brain tumors or breast cancer after exposure to high-frequency radiation? Review of methods and results of epidemiologic studies [German]. Med. Klin. 94, 150-158.

Blot, W.J., Henderson, B.E., and Boice, J.D., Jr. (1999) Childhood cancer in relation to cured meat intake: Review of the epidemiological evidence. Nutr. Cancer 34, 111-118.

Boffetta, P., Tredaniel, J., and Greco, A. (2000) Risk of childhood cancer and adult lung cancer after childhood exposure to passive smoke: A metaanalysis. Environ. Health Perspect. 108, 73-82.

Bohnen, N.I., and Kurland, L.T. (1995) Brain tumor and exposure to pesticides in humans: A review of the epidemiologic data. J. Neurol. Sci. 132, 110-121.
Bondy, M., and Ligon, B.L. (1996) Epidemiology and etiology of intracranial meningiomas: A review. J. Neurooncol. 29, 197-205.

Bondy, M., Wiencke, J., Wrensch, M., and Kyritsis, A.P. (1994) Genetics of primary brain tumors: A review. J. Neurooncol. 18, 69-81.

Bondy, M.L., Kyritsis, A.P., Gu, J., de Andrade, M., Cunningham, J., Levin, V.A., Bruner, J.M., and Wei, Q. (1996) Mutagen sensitivity and risk of gliomas: A case-control analysis. Cancer Res. 56, 1484-1486.

Bondy, M.L., Wang, L.E., El-Zein, R., de Andrade, M., Selvan, M.S., Bruner, J.M., Levin, V.A., Yung, W.K.A., Adatto, P., and Wei, Q. (2001) Gammaradiation sensitivity and risk of glioma. J. Natl. Cancer Inst. 93, 1553-1557.

Brenner, A.V., Linet, M.S., Fine, H.A., Shapiro, W.R., Selker, R.G., Black, P.M., and Inskip, P.D. (2002) History of allergies and autoimmune diseases and risk of brain tumors in adults. Int. J. Cancer 99, 252-259.

Brinton, L.A., Lubin, J.H., Burich, M.C., Colton, T., Brown, S.L., and Hoover, R.N. (2001) Cancer risk at sites other than the breast following augmentation mammoplasty. Ann. Epidemiol. 11, 248-256.

Bunin, G. (2000) What causes childhood brain tumors? Limited knowledge, many clues. Pediatr. Neurosurg. 32, 321-326.

Burch, J.D., Craib, K.J., Choi, B.C., Miller, A.B., Risch, H.A., and Howe, G.R. (1987) An exploratory case-control study of brain tumors in adults. J. Natl. Cancer Inst. 78, 601-609.

Burnett, C., Robinson, C., and Walker, J. (1999) Cancer mortality in health and science technicians. Am. J. Ind. Med. 36, 155-158.

Caggana, M., Kilgallen, J., Conroy, J.M., Wiencke, J.K., Kelsey, K.T., Miike, R., Chen, P., and Wrensch, M.R. (2001) Associations between ERCC2 polymorphisms and gliomas. Cancer Epidemiol. Biomarkers Prev. 10, 355-360.

Cairncross, J.G., Ueki, K., Zlatescu, M.C., Lisle, D.K., Finkelstein, D.M., Hammond, R.R., Silver, J.S., Stark, P.C., Macdonald, D.R., Ino, Y., Ramsay, D.A., and Louis, D.N. (1998) Specific genetic predictors of chemotherapeutic response and survival in patients with anaplastic oligodendrogliomas. J. Natl. Cancer Inst. 90, 1473-1479.

Cantor, K.P., Lynch, C.F., Hildesheim, M.E., Dosemeci, M., Lubin, J., Alavanja, M., and Craun, G. (1999) Drinking water source and chlorination byproducts in lowa. III. Risk of brain cancer. Am. J. Epidemiol. 150, 552-560.

Carozza, S.E., Wrensch, M., Miike, R., Newman, B., Olshan, A.F., Savitz, D.A., Yost, M., and Lee, M. (2000) Occupation and adult glioma. Am. J. Epidemiol. 152, 838-846. 
CBTRUS (Central Brain Tumor Registry of the United States) (1998) 1997 Annual Report. Chicago: Central Brain Tumor Registry of the United States.

CBTRUS (Central Brain Tumor Registry of the United States) (2000) Statistical Report: Primary Brain Tumors in the United States 1992-1997. Chicago: Central Brain Tumor Registry of the United States.

CDC (Centers for Disease Control) (1990) Guidelines for Investigating Clusters of Health Events: Appendix: Summary of Methods for Statistically Assessing Clusters of Health Events. Atlanta: CDC.

Chen, P., Wiencke, J., Aldape, K., Kesler-Diaz, A., Miike, R., Kelsey, K., Lee, M., Liu, J., and Wrensch, M. (2000) Association of an ERCC1 polymorphism with adult-onset glioma. Cancer Epidemiol Biomarkers Prev. 9, 843-847.

Chen, P., Aldape, K., Wiencke, J.K., Kelsey, K.T., Miike, R., Davis, R.L., Liu, J., Kesler-Diaz, A., Takahashi, M., and Wrensch, M. (2001) Ethnicity delineates different genetic pathways in malignant glioma. Cancer Res. 61 3949-3954.

Choi, N.W., Schuman, L.M., and Gullen, W.H. (1970) Epidemiology of primary central nervous system neoplasms. II. Case-control study. Am. J. Epidemiol. 91, 467-485.

Clemmesen, J., and Hjalgrim-Jensen, S. (1978) Is phenobarbital carcinogenic? A follow-up of 8078 epileptics. Ecotoxicol. Environ. Saf. 1, 457-470.

Cocco, P., Heineman, E.F., and Dosemeci, M. (1999) Occupational risk factors for cancer of the central nervous system (CNS) among US women. Am. J. Ind. Med. 36, 70-74.

Codd, M.B., Kurland, L.T., O'Fallon, W.M., Beard, C.M., and Cascino, T.L. (1990) Case-control study of neuroepithelial tumors in Rochester, Minnesota, 1950-1977. Neuroepidemiology 9, 17-26.

Cooper, S.P., Labarthe, D., Downs, T., Burau, K., Whitehead, L., Vernon, S., Spitz, M., New, B., and Sigurdson, A. (1997) Cancer mortality among petroleum refinery and chemical manufacturing workers in Texas. J. Environ. Pathol. Toxicol. Oncol. 16, 1-14.

Cuomo, L., Trivedi, P., Cardillo, M.R., Gagliardi, F.M., Vecchione, A., Caruso, R., Calogero, A., Frati, L., Faggioni, A., and Ragona, G. (2001) Human herpesvirus 6 infection in neoplastic and normal brain tissue. J. Med. Virol. 63, 45-51.

Curran, W.J., Jr., Scott, C.B., Horton, J., Nelson, J.S., Weinstein, A.S., Fischbach, A.J., Chang, C.H., Rotman, M., Asbell, S.O., Krisch, R.E., and Nelson, D.F. (1993) Recursive partitioning analysis of prognostic factors in three Radiation Therapy Oncology Group malignant glioma trials. J. Natl. Cancer Inst. 85, 704-710.

Davis, F.G., and McCarthy, B.J. (2000) Epidemiology of brain tumors. Curr. Opin. Neurol. 13, 635-640.

Davis, F.G., and Preston-Martin, S. (1998) Epidemiology: Incidence and survival. In: Bigner, D.D., McLendon, R.E., and Bruner, J.M. (Eds.), Russell and Rubinstein's Pathology of Tumors of the Nervous System. Sixth edition. London: Oxford University Press. pp. 5-45.

Davis, F.G., Bruner, J.M., and Surawicz, T.S. (1997) The rationale for standardized registration and reporting of brain and central nervous system tumors in population-based cancer registries. Neuroepidemiology 16, 308-316.

Davis, F.G., Freels, S., Grutsch, J., Barlas, S., and Brem, S. (1998) Survival rates in patients with primary malignant brain tumors stratified by patient age and tumor histological type: An analysis based on Surveillance, Epidemiology, and End Results (SEER) data, 1973-1991. J. Neurosurg. 88, 1-10.

Davis, F.G., McCarthy, B., and Jukich, P. (1999a) The descriptive epidemiology of brain tumors. Neuroimaging Clin. N. Am. 9, 581-594.

Davis, F.G., McCarthy, B.J., Freels, S., Kupelian, V., and Bondy, M.L. (1999b) The conditional probability of survival of patients with primary malignant brain tumors: Surveillance, epidemiology, and end results (SEER) data. Cancer 85, 485-491.

Davis, F.G., Kupelian, V., Freels, S., McCarthy, B., and Surawicz, T. (2001) Prevalence estimates for primary brain tumors in the United States by behavior and major histology groups. Neuro-oncol. 3, 152-158.
Davis, S., Kaune, W.T., Mirick, D.K., Chen, C., and Stevens, R.G. (2001) Residential magnetic fields, light-at-night, and nocturnal urinary 6-sulfatoxymelatonin concentration in women. Am. J. Epidemiol. 154, 591-600.

de Andrade, M., Barnholtz, J.S., Amos, C.I., Adatto, P., Spencer, C., and Bondy, M.L. (2001) Segregation analysis of cancer in families of glioma patients. Genet. Epidemiol. 20, 258-270.

Del Valle, L., Gordon, J., Assimakopoulou, M., Enam, S., Geddes, J.F., Varakis, J.N., Katsetos, C.D., Croul, S., and Khalili, K. (2001) Detection of JC virus DNA sequences and expression of the viral regulatory protein T-antigen in tumors of the central nervous system. Cancer Res. 61, 4287-4293.

Delzell, E., Beall, C., Rodu, B., Lees, P.S., Breysse, P.N., and Cole, P. (1999) Case-series investigation of intracranial neoplasms at a petrochemical research facility. Am. J. Ind. Med. 36, 450-458.

Demers, P.A., Vaughan, T.L., and Schommer, R.R. (1991) Occupation, socioeconomic status, and brain tumor mortality: A death certificate-based casecontrol study. J. Occup. Med. 33, 1001-1006.

Demers, P.A., Heyer, N.J., and Rosenstock, L. (1992) Mortality among firefighters from three northwestern United States cities. Br. J. Ind. Med. $49,664-670$

Demers, P.A., Checkoway, H., Vaughan, T.L., Weiss, N.S., Heyer, N.J., and Rosenstock, L. (1994) Cancer incidence among firefighters in Seattle and Tacoma, Washington (United States). Cancer Causes Control 5, 129-135.

Deschamps, S., Momas, I., and Festy, B. (1995) Mortality amongst Paris firefighters. Eur. J. Epidemiol. 11, 643-646.

Devesa, S.S., Grauman, D.G., Blot, W.J., Pennello, G., Hoover, R.N., and Fraumeni, J.F. (1999) Atlas of Cancer Mortality in the United States, 1950-94. Washington, DC: National Institute of Health, National Cancer Institute.

Divine, B.J., and Hartman, C.M. (2000) Update of a study of crude oil production workers 1946-94. Occup. Environ. Med. 57, 411-417.

Divine, B.J., Hartman, C.M., and Wendt, J.K. (1999) Update of the Texaco mortality study 1947-93. I. Analysis of overall patterns of mortality among refining, research, and petrochemical workers. Occup. Environ. Med. 56, 167-173.

Elexpuru-Camiruaga, J., Buxton, N., Kandula, V., Dias, P.S., Campbell, D., McIntosh, J., Broome, J., Jones, P., Inskip, A., Alldersea, J., Fryer, A.A., and Strange, R.C. (1995) Susceptibility to astrocytoma and meningioma: Influence of allelism at glutathione S-transferase (GSTT1 and GSTM1) and cytochrome P-450 (CYP2D6) loci. Cancer Res. 55, 4237-4239.

Farwell, J.R., Dohrmann, G.J., and Flannery, J.T. (1984) Medulloblastoma in childhood: An epidemiological study. J. Neurosurg. 61, 657-664.

Feychting, M., Floderus, B., and Ahlbom, A. (2000) Parental occupational exposure to magnetic fields and childhood cancer (Sweden). Cancer Causes Control 11, 151-156.

Firth, H.M., Cooke, K.R., and Herbison, G.P. (1996) Male cancer incidence by occupation: New Zealand, 1972-1984. Int. J. Epidemiol. 25, 14-21.

Fisher, J.L., Schwartzbaum, J.A., and Johnson, C.C. (2000) Cold/influenza infection, influenza vaccination, and risk of adult glioma. Am. J. Epidemiol. 151, S29. (Abstract)

Fisher, S.G., Weber, L., and Carbone, M. (1999) Cancer risk associated with simian virus 40 contaminated polio vaccine. Anticancer Res. 19, 2173-2180.

Floderus, B., Stenlund, C., and Persson, T. (1999) Occupational magnetic field exposure and site-specific cancer incidence: A Swedish cohort study. Cancer Causes Control 10, 323-332.

Fremgen, A.M., Bland, K.I., McGinnis, L.S., Jr., Eyre, H.J., McDonald, C.J., Menck, H.R., and Murphy, G.P. (1999) Clinical highlights from the National Cancer Data Base, 1999. CA: Cancer J. Clin. 49, 145-158.

Gao, L., Liu, L., van Meyel, D., Cairncross, G., Forsyth, P., Kimmel, D., Jenkins, R.B., Lassam, N.J., and Hogg, D. (1997) Lack of germ-line mutations of CDK4, p16(INK4A), and p15(INK4B) in families with glioma. Clin. Cancer Res. 3, 977-981.

Gavin, P., and Yogev, R. (1999) Central nervous system abnormalities in pediatric 
human immunodeficiency virus infection. Pediatr. Neurosurg. 31, 115-123.

Geissler, E., and Staneczek, W. (1988) SV40 and human brain tumors. Arch. Geschwulstforschung. 58, 129-134.

Glaser, S.L., Satariano, E., Leung, R.W., Prehn, A.W., Cady, C.M., and West, D.W. (Eds.) (1996) Cancer Incidence by Race/Ethnicity in the San Francisco Bay Area: Twenty Years of Cancer Reporting 1973-1992. Union City, Calif.: Northern California Cancer Center.

Golden, A.L., Markowitz, S.B., and Landrigan, P.J. (1995) The risk of cancer in firefighters. Occup. Med. 10, 803-820.

Grossman, S.A., Osman, M., Hruban, R., and Piantadosi, S. (1999) Central nervous system cancers in first-degree relatives and spouses. Cancer Invest. 17, 299-308.

Grotzer, M.A., Janss, A.J., Phillips, P.C., and Trojanowski, J.Q. (2000) Neurotrophin receptor TrkC predicts good clinical outcome in medulloblastoma and other primitive neuroectodermal brain tumors. Klin. Padiatr. 212, 196-199.

Grotzer, M.A., Geoerger, B., Janss, A.J., Zhao, H., Rorke, L.B., and Phillips, P.C. (2001) Prognostic significance of Ki-67 (MIB-1) proliferation index in childhood primitive neuroectodermal tumors of the central nervous system. Med. Pediatr. Oncol. 36, 268-273.

Grovas, A., Fremgen, A., Rauck, A., Ruymann, F.B., Hutchinson, C.L., Winchester, D.P., and Menck, H.R. (1997) The National Cancer Data Base report on patterns of childhood cancers in the United States. Cancer $\mathbf{8 0}$, 2321-2332.

Guidotti, T.L. (1995) Occupational mortality among firefighters: Assessing the association. J. Occup. Environ. Med. 37, 1348-1356.

Gundestrup, M., and Storm, H.H. (1999) Radiation-induced acute myeloid leukaemia and other cancers in commercial jet cockpit crew: A populationbased cohort study. Lancet 354, 2029-2031.

Gurney, J.G., Preston-Martin, S., McDaniel, A.M., Mueller, B.A., and Holly, E.A. (1996) Head injury as a risk factor for brain tumors in children: Results from a multicenter case-control study. Epidemiology 7, 485-489.

Gurney, J.G., Wall, D.A., Jukich, P.J., and Davis, F.G. (1999) The contribution of nonmalignant tumors to CNS tumor incidence rates among children in the United States. Cancer Causes Control 10, 101-105.

Hagel, C., Krog, B., Laas, R., and Stavrou, D.K. (1999) Prognostic relevance of TP53 mutations, p53 protein, Ki-67 index and conventional histological grading in oligodendrogliomas. J. Exp. Clin. Cancer Res. 18, 305-309.

Hagmar, L., Akesson, B., Nielsen, J., Andersson, C., Lindén, K., Attewell, R., and Möller, T. (1990) Mortality and cancer morbidity in workers exposed to low levels of vinyl chloride monomer at a polyvinyl chloride processing plant. Am. J. Ind. Med. 17, 553-565.

Hardell, L., Nasman, A., Pahlson, A., Hallquist, A., and Hansson Mild, K. (1999) Use of cellular telephones and the risk for brain tumours: A casecontrol study. Int. J. Oncol. 15, 113-116.

Hardell, L., Mild, K.H., Pahlson, A., and Hallquist, A. (2001) lonizing radiation, cellular telephones and the risk for brain tumours. Eur. J. Cancer Prev. 10, 523-529.

Helseth, A. (1995) The incidence of primary central nervous system neoplasms before and after computerized tomography availability. J. Neurosurg. 83, 999-1003.

Hemminki, K., Li, X., Vaittinen, P., and Dong, C. (2000) Cancers in the firstdegree relatives of children with brain tumours. Br. J. Cancer 83, 407-411.

Hjalmars, U., Kulldorff, M., Wahlqvist, Y., and Lannering, B. (1999) Increased incidence rates but no space-time clustering of childhood astrocytoma in Sweden, 1973-1992: A population-based study of pediatric brain tumors. Cancer 85, 2077-2090.

Hodges, L.C., Smith, J.L., Garrett, A., and Tate, S. (1992) Prevalence of glioblastoma multiforme in subjects with prior therapeutic radiation. J. Neurosci. Nurs. 24, 79-83.

Holly, E.A., Bracci, P.M., Mueller, B.A., and Preston-Martin, S. (1998) Farm and animal exposures and pediatric brain tumors: Results from the United
States West Coast Childhood Brain Tumor Study. Cancer Epidemiol. Biomarkers Prev. 7, 797-802.

Horn, B., Heideman, R., Geyer, R., Pollack, I., Packer, R., Goldwein, J., Tomita, T., Schomberg, P., Ater, J., Luchtman-Jones, L., Rivlin, K., Lamborn, K., Prados, M., Bollen, A., Berger, M., Dahl, G., McNeil, E., Patterson, K., Shaw, D., Kubalik, M., and Russo, C. (1999) A multi-institutional retrospective study of intracranial ependymoma in children: Identification of risk factors. J. Pediatr. Hematol. Oncol. 21, 203-211.

Hu, J., La Vecchia, C., Negri, E., Chatenoud, L., Bosetti, C., Jia, X., Liu, R., Huang, G., Bi, D., and Wang, C. (1999) Diet and brain cancer in adults: A case-control study in northeast China. Int. J. Cancer 81, 20-23.

Hu, J., Mao, Y., and Ugnat, A.M. (2000) Parental cigarette smoking, hard liquor consumption and the risk of childhood brain tumors-a casecontrol study in northeast China. Acta Oncol. 39, 979-984.

Huncharek, M., and Kupelnick, B. (2000) Epidermal growth factor receptor gene amplification as a prognostic marker in glioblastoma multiforme: Results of a meta-analysis. Oncol. Res. 12, 107-112.

Inskip, P.D., Linet, M.S., and Heineman, E.F. (1995) Etiology of brain tumors in adults. Epidemiol. Rev. 17, 382-414.

Inskip, P.D., Mellemkjaer, L., Gridley, G., and Olsen, J.H. (1998) Incidence of intracranial tumors following hospitalization for head injuries (Denmark). Cancer Causes Control 9, 109-116.

Inskip, P.D., Tarone, R.E., Hatch, E.E., Wilcosky, T.C., Shapiro, W.R., Selker, R.G., Fine, H.A., Black, P.M., Loeffler, J.S., and Linet, M.S. (2001) Cellulartelephone use and brain tumors. N. Engl. J. Med. 344, 79-86.

Irvine, D., and Davies, D.M. (1999) British Airways flightdeck mortality study, 1950-1992. Aviat. Space Environ. Med. 70, 548-555.

James, C.D., Smith, J.S., and Jenkins, R.B. (2002) Genetic and molecular basis of primary central nervous system tumors. In: Levin, V. (Ed.), Cancer in the Nervous System. Second edition. New York: Oxford University Press. pp. 239-251.

Johansen, C., and Olsen, J.H. (1999) Risk of cancer among Danish electricity workers: A cohort study [Danish]. Ugeskr. Laeger 161, 2079-2085.

Johansen, C., Boice, J.D., Jr., McLaughlin, J.K., and Olsen, J.H. (2001) Cellular telephones and cancer-a nationwide cohort study in Denmark. J. Natl. Cancer Inst. 93, 203-207.

Jukich, P.J., McCarthy, B.J., Surawicz, T.S., Freels, S., and Davis, F.G. (2001) Trends in incidence of primary brain tumors in the United States, 19851994. Neuro-oncol. [serial online], Doc. 00-055, June 5, 2001. URL http://neuro-oncology.mc.duke.edu. Neuro-oncol. 3, 141-151.

Kaplan, S., Novikov, I., and Modan, B. (1997) Nutritional factors in the etiology of brain tumors: Potential role of nitrosamines, fat, and cholesterol. Am. J. Epidemiol. 146, 832-841.

Karak, A.K., Singh, R., Tandon, P.N., and Sarkar, C. (2000) A comparative survival evaluation and assessment of interclassification concordance in adult supratentorial astrocytic tumors. Pathol. Oncol. Res. 6, 46-52.

Karlsson, P., Holmberg, E., Lundell, M., Mattsson, A., Holm, L.E., and Wallgren, A. (1998) Intracranial tumors after exposure to ionizing radiation during infancy: A pooled analysis of two Swedish cohorts of 28,008 infants with skin hemangioma. Radiat. Res. 150, 357-364.

Kelsey, K.T., Wrensch, M., Zuo, Z.F., Miike, R., and Wiencke, J.K. (1997) A population-based case-control study of the CYP2D6 and GSTT1 polymorphisms and malignant brain tumors. Pharmacogenetics 7, 463-468.

Kheifets, L.I., Afifi, A.A., Buffler, P.A., and Zhang, Z.W. (1995) Occupational electric and magnetic field exposure and brain cancer: A meta-analysis. J. Occup. Environ. Med. 37, 1327-1341.

Kheifets, L.I., Sussman, S.S., and Preston-Martin, S. (1999) Childhood brain tumors and residential electromagnetic fields (EMF). Rev. Environ. Contam. Toxicol. 159, 111-129.

Khuder, S.A., Mutgi, A.B., and Schaub, E.A. (1998) Meta-analyses of brain cancer and farming. Am. J. Ind. Med. 34, 252-260.

Kleihues, P., and Ohgaki, H. (2000) Phenotype vs genotype in the evolution of 
astrocytic brain tumors. Toxicol. Pathol. 28, 164-170.

Krewski, D., Byus, C.V., Glickman, B.W., Lotz, W.G., Mandeville, R., McBride, M.L., Prato, F.S., and Weaver, D.F. (2001) Recent advances in research on radiofrequency fields and health. J. Toxicol. Environ. Health B Crit. Rev. 4, 145-159.

Kristensen, P., Andersen, A., Irgens, L.M., Bye, A.S., and Sundheim, L. (1996) Cancer in offspring of parents engaged in agricultural activities in Norway: Incidence and risk factors in the farm environment. Int. J. Cancer 65 39-50.

Krynska, B., Del Valle, L., Croul, S., Gordon, J., Katsetos, C.D., Carbone, M., Giordano, A., and Khalili, K. (1999) Detection of human neurotropic JC virus DNA sequence and expression of the viral oncogenic protein in pediatric medulloblastomas. Proc. Natl. Acad. Sci. U.S.A. 96, 11519-11524.

Kyritsis, A.P., Bondy, M.L., Xiao, M., Berman, E.L., Cunningham, J.E., Lee, P.S., Levin, V.A., and Saya, H. (1994) Germline p53 gene mutations in subsets of glioma patients. J. Natl. Cancer Inst. 86, 344-349.

Lee, M., Wrensch, M., and Miike, R. (1997) Dietary and tobacco risk factors for adult onset glioma in the San Francisco Bay Area (California, USA) Cancer Causes Control 8, 13-24.

Legler, J.M., Ries, L.A., Smith, M.A., Warren, J.L., Heineman, E.F., Kaplan, R.S., and Linet, M.S. (1999) Cancer surveillance series [corrected]: Brain and other central nervous system cancers: Recent trends in incidence and mortality. J. Natl. Cancer Inst. 91, 1382-1390.

Levallois, P., Dumont, M., Touitou, Y., Gingras, S., Mâsse, B., Gauvin, D., Kröger, E., Bourdages, M., and Douville, P. (2001) Effects of electric and magnetic fields from high-power lines on female urinary excretion of 6-sulfatoxymelatonin concentration in women. Am. J. Epidemiol. 154, 601-609

Lewis, R. (2001) Use of rank-order analysis of ordinal exposure data: Application to vinyl chloride exposure. Appl. Occup. Environ. Hyg. 16, 188-191.

Li, Y., Millikan, R.C., Carozza, S., Newman, B., Liu, E., Davis, R., Miike, R., and Wrensch, M. (1998) p53 mutations in malignant gliomas. Cancer Epidemiol. Biomarkers Prev. 7, 303-308.

Linet, M.S., Ries, L.A., Smith, M.A., Tarone, R.E., and Devesa, S.S. (1999) Cancer surveillance series: Recent trends in childhood cancer incidence and mortality in the United States. J. Natl. Cancer Inst. 91, 1051-1058.

Linos, A., Kardara, M., Kosmidis, H., Katriou, D., Hatzis, C., Kontzoglou, M., Koumandakis, E., and Tzartzatou-Stathopoulou, F. (1998) Reported influenza in pregnancy and childhood tumour. Eur. J. Epidemiol. 14, 471-475.

Little, M.P., de Vathaire, F., Shamsaldin, A., Oberlin, O., Campbell, S., Grimaud, E., Chavaudra, J., Haylock, R.G., and Muirhead, C.R. (1998) Risks of brain tumour following treatment for cancer in childhood: Modification by genetic factors, radiotherapy and chemotherapy. Int. J. Cancer. 78, 269-275.

Loning, L., Zimmermann, M., Reiter, A., Kaatsch, P., Henze, G., Riehm, H., and Schrappe, M. (2000) Secondary neoplasms subsequent to BerlinFrankfurt-Munster therapy of acute lymphoblastic leukemia in childhood: Significantly lower risk without cranial radiotherapy. Blood 95, 27702775.

Loomis, D.P., and Wolf, S.H. (1996) Mortality of workers at a nuclear materials production plant at Oak Ridge, Tennessee, 1947-1990. Am. J. Ind Med. 29, 131-141.

Lopez-Gonzalez, M.A., and Sotelo, J. (2000) Brain tumors in Mexico: Characteristics and prognosis of glioblastoma. Surg. Neurol. 53, 157-162.

Lote, K., Stenwig, A.E., Skullerud, K., and Hirschberg, H. (1998) Prevalence and prognostic significance of epilepsy in patients with gliomas. Eur. J. Cancer 34, 98-102.

Lubin, F., Farbstein, H., Chetrit, A., Farbstein, M., Freedman, L., Alfandary, E., and Modan, B. (2000) The role of nutritional habits during gestation and child life in pediatric brain tumor etiology. Int. J. Cancer 86, 139-143.

Ma, F., Lee, D.J., Fleming, L.E., and Dosemeci, M. (1998) Race-specific cancer mortality in US firefighters: 1984-1993. J. Occup. Environ. Med. 40,
1134-1138.

Malmer, B., Gronberg, H., Bergenheim, A.T., Lenner, P., and Henriksson, R. (1999) Familial aggregation of astrocytoma in northern Sweden: An epidemiological cohort study. Int. J. Cancer 81, 366-370.

Malmer, B., Tavelin, B., Henriksson, R., and Gronberg, H. (2000) Primary brain tumours as second primary: A novel association between meningioma and colorectal cancer. Int. J. Cancer 85, 78-81.

Malmer, B., Iselius, L., Holmberg, E., Collins, A., Henriksson, R., and Gronberg, H. (2001) Genetic epidemiology of glioma. Br. J. Cancer 84, 429-434.

McCarthy, B.J., Davis, F.G., Freels, S., Surawicz, T.S., Damek, D.M., Grutsch, J., Menck, H.R., and Laws, E.R., Jr. (1998) Factors associated with survival in patients with meningioma. J. Neurosurg. 88, 831-839.

McCredie, M., Little, J., Cotton, S., Mueller, B., Peris-Bonet, R., Choi, N.W., Cordier, S., Filippini, G., Holly, E.A., Modan, B., Arslan, A., and PrestonMartin, S. (1999) SEARCH international case-control study of childhood brain tumours: Role of index pregnancy and birth, and mother's reproductive history. Paediatr. Perinat. Epidemiol. 13, 325-341.

McKinley, B.P., Michalek, A.M., Fenstermaker, R.A., and Plunkett, R.J. (2000) The impact of age and sex on the incidence of glial tumors in New York state from 1976 to 1995. J. Neurosurg. 93, 932-939.

McLaughlin, J.K., and Lipworth, L. (1999) A critical review of the epidemiologic literature on health effects of occupational exposure to vinyl chloride. J. Epidemiol. Biostat. 4, 253-275.

Meinert, R., and Michaelis, J. (1996) Meta-analyses of studies on the association between electromagnetic fields and childhood cancer. Radiat. Environ. Biophys. 35, 11-18.

Minder, C.E., and Pfluger, D.H. (2001) Leukemia, brain tumors, and exposure to extremely low frequency electromagnetic fields in Swiss railway employees. Am. J. Epidemiol. 153, 825-835.

Mizumatsu, S., Tamiya, T., Ono, Y., Abe, T., Matsumoto, K., Furuta, T., and Ohmoto, T. (1999) Expression of cell cycle regulator p27Kip1 is correlated with survival of patients with astrocytoma. Clin. Cancer Res. 5, 551-557.

Mochizuki, S., Iwadate, Y., Namba, H., Yoshida, Y., Yamaura, A., Sakiyama, S., and Tagawa, M. (1999) Homozygous deletion of the p16/MTS-1/CDKN2 gene in malignant gliomas is infrequent among Japanese patients. Int. J. Oncol. 15, 983-989.

Moen, B.E., and Ovrebo, S. (1997) Assessment of exposure to polycyclic aromatic hydrocarbons during firefighting by measurement of urinary 1-hydroxypyrene. J. Occup. Environ. Med. 39, 515-519.

Morgan, R.W., Kelsh, M.A., Zhao, K., Exuzides, K.A., Heringer, S., and Negrete, W. (2000) Radiofrequency exposure and mortality from cancer of the brain and lymphatic/hematopoietic systems. Epidemiology 11, 118-127.

Mundt, K.A., Dell, L.D., Austin, R.P., Luippold, R.S., Noess, R., and Bigelow, C. (2000) Historical cohort study of 10109 men in the North American vinyl chloride industry, 1942-72: Update of cancer mortality to 31 December 1995. Occup. Environ. Med. 57, 774-781.

Muscat, J.E., Malkin, M.G., Thompson, S., Shore, R.E., Stellman, S.D., McRee, D., Neugut, A.I., and Wynder, E.L. (2000) Handheld cellular telephone use and risk of brain cancer. JAMA 284, 3001-3007.

Nakamura, M., Konishi, N., Tsunoda, S., Nakase, H., Tsuzuki, T., Aoki, H., Sakitani, H., Inui, T., and Sakaki, T. (2000) Analysis of prognostic and survival factors related to treatment of low-grade astrocytomas in adults. Oncology 58, 108-116.

Narod, S.A., Stiller, C., and Lenoir, G.M. (1991) An estimate of the heritable fraction of childhood cancer. Br. J. Cancer 63, 993-999.

Neglia, J.P., Meadows, A.T., Robison, L.L., Kim, T.H., Newton, W.A., Ruymann, F.B., Sather, H.N., and Hammond, G.D. (1991) Second neoplasms after acute lymphoblastic leukemia in childhood. N. Engl. J. Med. 325, 13301336

Nichols, K.E., Malkin, D., Garber, J.E., Fraumeni, J.F., Jr., and Li, F.P. (2001) Germ-line p53 mutations predispose to a wide spectrum of early-onset cancers. Cancer Epidemiol. Biomarkers Prev. 10, 83-87.

Neuro-Oncology - OCTOBER 2002 
NIEHS (1999) Health Effects from Exposure to Power-Line Frequency Electric and Magnetic Fields. NIH publication no. 99-4493. National Institute of Environmental Health Scences, National Institutes of Health.

Norman, M.A., Holly, E.A., and Preston-Martin, S. (1996) Childhood brain tumors and exposure to tobacco smoke. Cancer Epidemiol. Biomarkers Prev. 5, 85-91.

Olsen, J.H., Boice, J.D., Jr., Jensen, J.P., and Fraumeni, J.F., Jr. (1989) Cancer among epileptic patients exposed to anticonvulsant drugs. J. Natl. Cancer Inst. 81, 803-808.

Pace, A., Bove, L., Innocenti, P., Pietrangeli, A., Carapella, C.M., Oppido, P., Raus, L., Occhipinti, E., and Jandolo, B. (1998) Epilepsy and gliomas: Incidence and treatment in 119 patients. J. Exp. Clin. Cancer Res. 17, 479-482.

Peters, E.S., Kelsey, K.T., Wiencke, J.K., Park, S., Chen, P., Miike, R., and Wrensch, M.R. (2001) NAT2 and NQO1 polymorphisms are not associated with adult glioma. Cancer Epidemiol. Biomarkers Prev. 10, 151-152.

Pobereskin, L.H., and Chadduck, J.B. (2000) Incidence of brain tumours in two English counties: A population based study. J. Neurol. Neurosurg. Psychiatry 69, 464-471.

Pogoda, J.M., and Preston-Martin, S. (1997) Household pesticides and risk of pediatric brain tumors. Environ. Health Perspect. 105, 1214-1220.

Prados, M.D., Berger, M.S., and Wilson, C.B. (1998) Primary central nervous system tumors: Advances in knowledge and treatment. CA Cancer J. Clin. 48, 331-360, 321.

Preston-Martin, S., and Mack, W. (1996) Neoplasms of the nervous system. In: Schottenfeld, D., and Fraumeni, J.F., Jr. (Eds.), Cancer Epidemiology and Prevention. Second edition. New York: Oxford University Press. pp. 1231-1281.

Preston-Martin, S., Mack, W., and Henderson, B.E. (1989) Risk factors for gliomas and meningiomas in males in Los Angeles County. Cancer Res. 49, 6137-6143.

Preston-Martin, S., Pogoda, J.M., Schlehofer, B., Blettner, M., Howe, G.R., Ryan, P., Menegoz, F., Giles, G.G., Rodvall, Y., Choi, N.W., Little, J., and Arslan, A. (1998) An international case-control study of adult glioma and meningioma: The role of head trauma. Int. J. Epidemiol. 27, 579-586.

Raaschou-Nielsen, O., Hertel, O., Thomsen, B.L., and Olsen, J.H. (2001) Air pollution from traffic at the residence of children with cancer. Am. J. Epidemiol. 153, 433-443.

Rachet, B., Partanen, T., Kauppinen, T., and Sasco, A.J. (2000) Cancer risk in laboratory workers: An emphasis on biological research. Am. J. Ind. Med. 38, 651-665

Rice, J.M., and Wilbourn, J.D. (2000) Tumors of the nervous system in carcinogenic hazard identification. Toxicol. Pathol. 28, 202-214.

Robinson, C.F., and Walker, J.T. (1999) Cancer mortality among women employed in fast-growing U.S. occupations. Am. J. Ind. Med. 36, 186192.

Robinson, C.F., Petersen, M., and Palu, S. (1999) Mortality patterns among electrical workers employed in the U.S. construction industry, 1982-1987. Am. J. Ind. Med. 36, 630-637.

Rodu, B., Delzell, E., Beall, C., and Sathiakumar, N. (2001) Mortality among employees at a petrochemical research facility. Am. J. Ind. Med. 39, 29-41.

Ryan, P., Lee, M.W., North, B., and McMichael, A.J. (1992) Risk factors for tumors of the brain and meninges: Results from the Adelaide Adult Brain Tumor Study. Int. J. Cancer 51, 20-27.

Ryan, P., Hurley, S.F., Johnson, A.M., Salzberg, M., Lee, M.W., North, J.B., McNeil, J.J., and McMichael, A.J. (1993) Tumours of the brain and presence of antibodies to Toxoplasma gondii. Int. J. Epidemiol. 22, 412-419.

Salminen, E., Pukkala, E., and Teppo, L. (1999) Second cancers in patients with brain tumours-impact of treatment. Eur. J. Cancer 35, 102-105.

Salvati, M., Artico, M., Caruso, R., Rocchi, G., Orlando, E.R., and Nucci, F. (1991) A report on radiation-induced gliomas. Cancer 67, 392-397.

Sant, M., van der Sanden, G., and Capocaccia, R. (1998) Survival rates for primary malignant brain tumours in Europe. EUROCARE Working Group. Eur. J. Cancer 34, 2241-2247.

Santana, V.S., Silva, M., and Loomis, D. (1999) Brain neoplasms among naval military men. Int. J. Occup. Environ. Health 5, 88-94.

Sathiakumar, N., Delzell, E., Rodu, B., Beall, C., and Myers, S. (2001) Cancer incidence among employees at a petrochemical research facility. J. Occup. Environ. Med. 43, 166-174.

Savitz, D.A., Cai, J., van Wijngaarden, E., Loomis, D., Mihlan, G., Dufort, V., Kleckner, R.C., Nylander-French, L., Kromhout, H., and Zhou, H. (2000) Case-cohort analysis of brain cancer and leukemia in electric utility workers using a refined magnetic field job-exposure matrix. Am. J. Ind. Med. 38, 417-425.

Schlehofer, B., Blettner, M., Becker, N., Martinsohn, C., and Wahrendorf, J. (1992) Medical risk factors and the development of brain tumors. Cancer 69, 2541-2547.

Schlehofer, B., Blettner, M., Preston-Martin, S., Niehoff, D., Wahrendorf, J., Arslan, A., Ahlbom, A., Choi, W.N., Giles, G.G., Howe, G.R., Little, J., Ménégoz, F., and Ryan, P. (1999) Role of medical history in brain tumour development: Results from the International Adult Brain Tumour Study. Int. J. Cancer 82, 155-160.

Schreinemachers, D.M. (2000) Cancer mortality in four northern wheatproducing states. Environ. Health Perspect. 108, 873-881.

Schuman, L.M., Choi, N.W., and Gullen, W.H. (1967) Relationship of central nervous system neoplasms to Toxoplasma gondii infection. Am. J. Public Health Nations Health 57, 848-856.

Scott, J.N., Rewcastle, N.B., Brasher, P.M., Fulton, D., MacKinnon, J.A., Hamilton, M., Cairncross, J.G., and Forsyth, P. (1999) Which glioblastoma multiforme patient will become a long-term survivor? A population-based study. Ann. Neurol. 46, 183-188.

Shadan, F.F., and Koziol, J. (2000) Induced genome instability as a potential screening test for cancer susceptibility? Med. Hypotheses 55, 6972.

Shapiro, S., Mealey, J., Jr., and Sartorius, C. (1989) Radiation-induced intracranial malignant gliomas. J. Neurosurg. 71, 77-82.

Shintani, T., Hayakawa, N., Hoshi, M., Sumida, M., Kurisu, K., Oki, S., Kodama, Y., Kajikawa, H., Inai, K., and Kamada, N. (1999) High incidence of meningioma among Hiroshima atomic bomb survivors. J. Radiat. Res. 40, 49-57.

Shirts, S.B., Annegers, J.F., Hauser, W.A., and Kurland, L.T. (1986) Cancer incidence in a cohort of patients with seizure disorders. J. Natl. Cancer Inst. 77, 83-87.

Simmons, M.L., Lamborn, K.R., Takahashi, M., Chen, P., Israel, M.A., Berger, M.S., Godfrey, T., Nigro, J., Prados, M., Chang, S., Barker, F.G., II, and Aldape, K. (2001) Analysis of complex relationships between age, p53, epidermal growth factor receptor, and survival in glioblastoma patients. Cancer Res. 61, 1122-1128.

Simonato, L., L'Abbé, K.A., Andersen, A., Belli, S., Comba, P., Engholm, G., Ferro, G., Hagmar, L., Langård, S., Lundberg, I., Piratsu, R., Thomas, P., Winkleman, R., and Saracci, R. (1991) A collaborative study of cancer incidence and mortality among vinyl chloride workers. Scand. J. Work Environ. Health 17, 159-169.

Singh, G.K., and Siahpush, M. (2001) All-cause and cause-specific mortality of immigrants and native born in the United States. Am. J. Public Health 91, 392-399.

Smith, M.A., Freidlin, B., Ries, L.A., and Simon, R. (1998) Trends in reported incidence of primary malignant brain tumors in children in the United States. J. Natl. Cancer Inst. 90, 1269-1277.

Smith, M.A., Freidlin, B., Ries, L.A.G., and Simon, R. (1999) Response: Re: 
Trends in reported incidence of primary malignant brain tumors in children in the United States. J. Natl. Cancer Inst. 91, 973-974.

Socie, G., Curtis, R.E., Deeg, H.J., Sobocinski, K.A., Filipovich, A.H., Travis, L.B., Sullivan, K.M., Rowlings, P.A., Kingma, D.W., Banks, P.M., Travis, W.D., Witherspoon, R.P., Sanders, J., Jaffe, E.S., and Horowitz, M.M (2000) New malignant diseases after allogeneic marrow transplantation for childhood acute leukemia. J. Clin. Oncol 18, 348-357.

Sorahan, T., Hamilton, L., Gardiner, K., Hodgson, J.T., and Harrington, J.M. (1999) Maternal occupational exposure to electromagnetic fields before, during, and after pregnancy in relation to risks of childhood cancers: Findings from the Oxford Survey of Childhood Cancers, 1953-1981 deaths. Am. J. Ind. Med. 35, 348-357.

Straif, K., Weiland, S.K., Bungers, M., Holthenrich, D., Taeger, D., Yi, S., and Keil, U. (2000) Exposure to high concentrations of nitrosamines and cancer mortality among a cohort of rubber workers. Occup. Environ. Med. 57, 180-187.

Strauss, D., Cable, W., and Shavelle, R. (1999) Causes of excess mortality in cerebral palsy. Dev. Med. Child Neurol. 41, 580-585.

Strickler, H.D., Rosenberg, P.S., Devesa, S.S., Hertel, J., Fraumeni, J.F., Jr., and Goedert, J.J. (1998) Contamination of poliovirus vaccines with simian virus 40 (1955-1963) and subsequent cancer rates. JAMA 279, 292-295.

Strojnik, T., Kos, J., Zidanik, B., Golouh, R., and Lah, T. (1999) Cathepsin B immunohistochemical staining in tumor and endothelial cells is a new prognostic factor for survival in patients with brain tumors. Clin. Cancer Res. 5, 559-567.

Surawicz, T.S., McCarthy, B.J., Kupelian, V., Jukich, P.J., Bruner, J.M., and Davis, F.G. (1999) Descriptive epidemiology of primary brain and CNS tumors: Results from the Central Brain Tumor Registry of the United States, 1990-1994. Neuro-oncol. [serial online], Doc. 98-13, January 19, 1999. URL neuro-oncology.mc.duke.edu. Neuro-oncol. 1, 14-25.

Taiwo, B.O. (2000) AIDS-related primary CNS lymphoma: A brief review. AIDS Read. 10, 486-491.

Tedeschi-Blok, N., Schwartzbaum, J., Lee, M., Miike, R., and Wrensch, M. (2001) Dietary calcium consumption and astrocytic glioma: San Francisco Bay Area Adult Glioma Study, 1991-1995. Nutr. Cancer 39, 196-203.

Teppo, L., Salminen, E., and Pukkala, E. (2001) Risk of a new primary cancer among patients with lung cancer of different histological types. Eur. J. Cancer 37, 613-619.

Thomas, T.L., and Waxweiler, R.J. (1986) Brain tumors and occupational risk factors. Scand. J. Work Environ. Health 12, 1-15.

Tornling, G., Gustavsson, P., and Hogstedt, C. (1994) Mortality and cancer incidence in Stockholm fire fighters. Am. J. Ind. Med. 25, 219-228.

Trizna, Z., de Andrade, M., Kyritsis, A.P., Briggs, K., Levin, V.A., Bruner, J.M., Wei, Q., and Bondy, M.L. (1998) Genetic polymorphisms in glutathione Stransferase mu and theta, $\mathrm{N}$-acetyltransferase, and CYP1A1 and risk of gliomas. Cancer Epidemiol. Biomarkers Prev. 7, 553-555.

Varner, A. (1999) Re: Trends in reported incidence of primary malignant brain tumors in children in the United States. J. Natl. Cancer Inst. 91, 973-974.

Vena, J.E., and Fiedler, R.C. (1987) Mortality of a municipal-worker cohort. IV. Fire fighters. Am. J. Ind. Med. 11, 671-684.

Weiland, S.K., Mundt, K.A., Keil, U., Kraemer, B., Birk, T., Person, M., Bucher, A.M., Straif, K., Schumann, J., and Chambless, L. (1996) Cancer mortality among workers in the German rubber industry: 1981-91. Occup. Environ. Med. 53, 289-298.

Wennborg, H., Yuen, J., Axelsson, G., Ahlbom, A., Gustavsson, P., and Sasco, A.J. (1999) Mortality and cancer incidence in biomedical laboratory personnel in Sweden. Am. J. Ind. Med. 35, 382-389.

White, S.J., McLean, A.E., and Howland, C. (1979) Anticonvulsant drugs and cancer: A cohort study in patients with severe epilepsy. Lancet 2, 458-461.

Wiemels, J.L., Wiencke, J.K., Sison, J.D., Miike, R., McMillan, A., and Wrensch, M. (2002) History of allergies among adults with glioma and controls. Int. J. Cancer 98, 609-615.

Wong, O., and Raabe, G.K. (2000) A critical review of cancer epidemiology in the petroleum industry, with a meta-analysis of a combined database of more than 350,000 workers. Regul. Toxicol. Pharmacol. 32, 78-98.

Wong, O., Whorton, M.D., Foliart, D.E., and Ragland, D. (1991) An industrywide epidemiologic study of vinyl chloride workers, 1942-1982. Am. J. Ind. Med. 20, 317-334.

Wrensch, M., Bondy, M.L., Wiencke, J., and Yost, M. (1993) Environmental risk factors for primary malignant brain tumors: A review. J. Neurooncol. $17,47-64$.

Wrensch, M., Lee, M., Miike, R., Newman, B., Barger, G., Davis, R., Wiencke, J., and Neuhaus, J. (1997) Familial and personal medical history of cancer and nervous system conditions among adults with glioma and controls. Am. J. Epidemiol. 145, 581-593.

Wrensch, M., Yost, M., Miike, R., Lee, G., and Touchstone, J. (1999) Adult glioma in relation to residential power frequency electromagnetic field exposures in the San Francisco Bay area. Epidemiology 10, 523-527.

Wrensch, M.R., Minn, Y., and Bondy, M.L. (2000a) Edpidemiology. In: Bernstein, M., and Berger, M.S. (Eds.), Neuro-Oncology: The Essentials. New York: Thieme Medical Publishers. pp. 2-17.

Wrensch, M., Miike, R., Lee, M., and Neuhaus, J. (2000b) Are prior head injuries or diagnostic $x$-rays associated with glioma in adults? The effects of control selection bias. Neuroepidemiology 19, 234-244.

Wrensch, M., Weinberg, A., Wiencke, J., Miike, R., Barger, G., and Kelsey, K. (2001) Prevalence of antibodies to four herpesviruses among adults with glioma and controls. Am. J. Epidemiol. 154, 161-165.

Wu, W., Steenland, K., Brown, D., Wells, V., Jones, J., Schulte, P., and Halperin, W. (1989) Cohort and case-control analyses of workers exposed to vinyl chloride: An update. J. Occup. Med. 31, 518-523.

Yeh, H., Matanoski, G.M., Wang, N., Sandler, D.P., and Comstock, G.W. (2001) Cancer incidence after childhood nasopharyngeal radium irradiation: A follow-up study in Washington County, Maryland. Am. J. Epidemiol. 153, 749-756.

Zahm, S.H. (1999) Childhood leukemia and pesticides. Epidemiology 10, 473-475.

Zheng, T., Cantor, K.P., Zhang, Y., Keim, S., and Lynch, C.F. (2001) Occupational risk factors for brain cancer: A population-based case-control study in lowa. J. Occup. Environ. Med. 43, 317-324. 